Research Article

\title{
Bearing Damage Detection of a Bridge under the Uncertain Conditions Based on the Bayesian Framework and Matrix Perturbation Method
}

\author{
Baojun Li, ${ }^{1,2}$ Yongzhi Lei $\mathbb{D}^{3},{ }^{3}$ Dongming Zhou, ${ }^{4}$ Zhiheng Deng $\mathbb{D}^{1,2}$ Yuhou Yang, ${ }^{1,2}$ \\ and Minshui Huang $\mathbb{D}^{3}$ \\ ${ }^{1}$ College of Civil Engineering and Architecture, Guangxi University, Nanning 530004, China \\ ${ }^{2}$ Guangxi Transportation Science and Technology Group Co., Ltd., Nanning 530001, China \\ ${ }^{3}$ School of Civil Engineering and Architecture, Wuhan Institute of Technology, Wuhan 430074, China \\ ${ }^{4}$ Road Maintenance Center of Yulin, Yulin 537000, China
}

Correspondence should be addressed to Zhiheng Deng; 19840011@gxu.edu.cn and

Minshui Huang; huangminshui@tsinghua.org.cn

Received 1 March 2021; Revised 31 March 2021; Accepted 10 April 2021; Published 20 May 2021

Academic Editor: Yiwei Wang

Copyright (c) 2021 Baojun Li et al. This is an open access article distributed under the Creative Commons Attribution License, which permits unrestricted use, distribution, and reproduction in any medium, provided the original work is properly cited.

\begin{abstract}
The bearing of a bridge, as a critical component, is important in the force transformation of the superstructure; however, due to the service condition and repeated impact load, the bearing is prone to be damaged but difficult to detect the damage; the present research has few studies that focused on the damage detection of the structural bearing. Meanwhile, practical engineering is always surrounded by variational environmental conditions, and sometimes, the element and bearing damage both exist in the structure. Thus, these uncertain conditions all cause inaccurate damage identification results using the vibration-based damage detection method. In order to detect the damage of the structural bearing and improve the precision, firstly, the structural dynamic characteristic equation considering uncertain conditions has been deduced; then, a damage detection framework constructed by the Bayesian theory and perturbation method has been developed in this article; a numerical example of an 8-span concrete continuous beam and a practical example of I-40 steel-concrete composite bridge are utilized to validate the feasibility of the proposed method, and single type and two types of damage cases are studied. The outcomes demonstrate that the damage of structural elements and bearings can be detected with high accuracy. The proposed method is of great applicability and good potential.
\end{abstract}

\section{Introduction}

The bridge structure, as an important tool to connect the two sides of a river or valley, often suffers from heavy traffic flows [1] and serious impact loads. Due to the practical service situation of the bridge, the bridge bearing function, as a critical connector, can transfer the loads coming from bridge decks to bridge piers. The rubber bearings are exposed to the air, which are easy to be aged by the environmental factors [2]. At the same time, under the repeated load, the bearing has been very vulnerable further, which means some diseases, such as separation, shear deformation, bulging deformation, and transverse crack, have often emerged in this component.
When the diseases have occurred in the bridge bearings, the transmission of the force in the whole bridge will be changed; even, it will damage the deck and pier in some extreme cases. Thus, the destruction of the bearings will cause a potential risk to the service period of the bridge. Although numerous researchers pay attention to structural health monitoring (SHM), most ideas have focused on the structural element rather than the structural bearings [3-8], which means the research field of this critical component is blank, and it is necessary to put forward some solutions to detect the damage of bridge bearings.

Vibration-based structural damage identification methods have been obtained and widely used in various civil engineering examples $[9,10]$, which provide a possible 
solution to the bearing damage detection. Chen et al. [11] investigated the feasibility and sensitivity of bearing damage identification using bridge vibration modes and the radial basis function neural network; the results indicate that modal information can reflect the bearing damage clearly. $\mathrm{Ni}$ et al. [12] adopted correlation and sensitivity analysis to put forward a damage identification indicator of the bridge pot rubber bearing and then combined with the support vector machine to form a safety-level discriminant model to assess the health state of the bridge pot rubber bearing. However, because the influence severities of modal parameters to structural elements and bearings are discrepant and nonlinear, Huang et al. [13] conducted the modal parameter sensitivity analysis on the damage of structural elements and bridge bearings and deduced the sensitivity coefficients of eigenvalue to the damage factors of structural elements and bearings; then, the regularization method and chaotic mothflame-invasive weed optimization were used to identify the structural element and bearing damage simultaneously. The outcomes indicate that the accuracy still desires to be improved. Meanwhile, when the structural element and bearing damage have emerged in the structure simultaneously, how to detect the two types of damage accurately? It needs more thinking.

On the contrary, due to the tough service conditions of bridge structures, some environmental impacts, such as environmental temperature variations, traffic flow vibration, and climate and weather change, are always acting in structures [14]. All these factors can be considered as uncertainties of the damage identification process, which set the obstacle to identify damage precisely. Aiming to this hardship, Bayesian theory has been introduced in the field of SHM. For example, Ding et al. [15] adopted Bayesian inference and sparse regularization technology to modify the traditional objective function of damage identification; the numerical example and experimental studies show that the robustness is enhanced under the condition of significant uncertainty effect. Hou et al. [16] developed the spare Bayesian learning framework to simultaneously consider the uncertainties and varying temperature conditions; an experimental frame study demonstrated that the method is effective in locating and quantifying structural damage. Wang et al. [17] focused on different uncertainties of each mode in the sparse Bayesian method for damage identification, and variational Bayesian inference was developed; then, the high accuracy of the proposed method was validated by a laboratory-tested frame. Furthermore, the iterative process of Bayesian damage identification method needs to construct the finite element model repetitively, which means the computation is very time consuming. For this problem, one of the solutions is to develop the surrogate model, such as the kriging model [18], artificial neural network, [19] and perturbation model [20].

Regarding the present research, there are few studies that have focused on the bearing damage identification, even less to consider the uncertainties of bearing damage detection; thus, in this paper, a bearing damage detection method with good potential has been developed to identify the damage of structural elements and bearings simultaneously; compared to the previous research [13], the proposed one shows high accuracy. The main significance can be summarized as follows: (1) the structural dynamic characteristic equation considering uncertain conditions has been deduced, and then based on the resulting equation, the influences of uncertain conditions on the modal parameters of the simply supported beam have been investigated, which implies the uncertainties should be considered adequately in the damage identification; (2) the Bayesian theory and perturbation method are combined, which is successfully used to identify the damage of structural elements and bearings simultaneously under the influences of uncertainties; (3) only the first several natural frequencies and modal shapes are needed to carry out the proposed damage detection method, which shows good potential and broad applicability.

The specific research can be pointed as follows: first of all, based on the structural dynamics and finite element method, the structural dynamic characteristic equation considering bearing damage and environmental temperature variations, as well as element damage, has been obtained, the bearing damage is simulated by introducing the boundary stiffness matrix, and the temperature variations are transformed into elastic modulus decrease. Then, based on the dynamic characteristic equation, a simply supported beam is adopted to evaluate the influences of uncertainties to the modal parameters. After that, Bayesian theory is adopted, and combined with the structural dynamic characteristic equation considering uncertain conditions, the damage detection framework of structural elements and bearings has been formed; additionally, the perturbation method is introduced to avoid the repetitive construction of the finite element model. Finally, a numerical 8-span concrete continuous beam structure and a practical engineering example of I-40 steel-concrete composite bridge are utilized to validate the feasibility and applicability of the proposed framework. The damage detection results indicate that both single type of damage case (only element damage or bearing damage) and two types of damage case (both element and bearing damage) can be identified; furthermore, the influences of uncertainties have been overcome.

\section{The Evaluation of the Influences of Uncertain Conditions on Modal Parameters}

2.1. Structural Dynamic Characteristic Equation considering Uncertain Conditions. In order to assess the impacts on the measured modal parameters caused by uncertain conditions, in this section, as shown in Figure 1, the simply supported beam with spring support in each end has been introduced to conduct the research. The main function of bridge bearings is to transfer the load in the superstructure to the foundation; when the damage has occurred in this component, the stiffness of the bearing will be changed; thus, the bearings can be simplified and simulated as the simple spring models with the spring constants [21-25]. For the length of each element is $0.25 \mathrm{~m}$, its properties of material, such as Young's modulus, mass density, inertia moment, and cross-sectional area, are $3.0 \times 10^{10} \mathrm{~Pa}$, $2360 \mathrm{~kg} / \mathrm{m}^{3}, 8.64 \times 10^{-5} \mathrm{~m}^{4}$, and $0.072 \mathrm{~m}^{2}$, respectively; the spring constants of each end are $10^{6} \mathrm{~N} / \mathrm{m}$. 


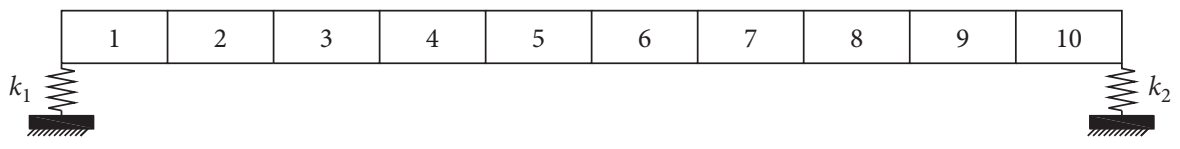

FIgURE 1: The simply supported beam.

Three factors have been investigated in this section, namely, structural element damage, boundary condition change (bearing damage), and environmental temperature variations. Assuming that the occurrence of damage does not cause the mass change, the structural element damage is simulated by the element stiffness reduction, which can be written as follows [26-29]:

$$
K_{s}=\sum_{i=1}^{\text {nele }}\left(1-\theta_{i}\right) k_{i}^{e}, \quad 0 \leq \theta_{i} \leq 1,
$$

where $K_{s}$ means the global stiffness matrix of a structure; nele denotes the total number of structural elements; and $k_{i}^{e}$ and $\theta_{i}$ are $i$-th element stiffness matrix and $i$-th stiffness reduction factor, respectively.

Meanwhile, the boundary condition change, namely, the damage of bearings, can be represented as the boundary condition matrix, and it can be defined as follows $[13,30]$ :

$$
\begin{array}{llllll}
U x & R x & U y & R y & R z
\end{array}
$$

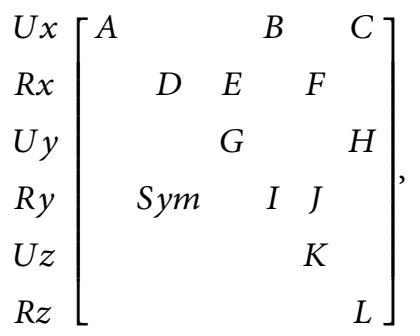

where the diagonal elements on the matrix represent the boundary stiffness in every degree of freedom (DOF); other elements can be described as the synergistic effects. The matrix can be utilized in the 2D finite element model by reducing the unconcerned DOFs. Thus, the damage in the structural bearings can also be described as the similar form as the structural element damage:

$$
K_{b c}=\sum_{j=1}^{n b c}\left(1-\alpha_{j}\right) k_{j}^{b c}, \quad 0 \leq \alpha_{j} \leq 1,
$$

where $K_{b c}$ means the global stiffness matrix of a structural boundary system; $n b c$ denotes the total number of bearings; and $k_{j}^{b c}$ and $\alpha_{j}$ are the $j$-th bearing stiffness matrix and $i$-th bearing stiffness reduction factor, respectively.

In addition, the environmental temperature variations have also been a serious impact on a civil structure, which can cause the fluctuation of the measured modal parameters $[31,32]$. In this paper, the temperature variation is transformed into the reduction of Young's modulus, which can be calculated as follows [33]:

$$
E(T)=E_{0} \cdot\left[1-\alpha_{E} \cdot\left(T-T_{0}\right)\right],
$$

where $E(T)$ and $E_{0}$ represent Young's modulus of the material at temperatures $T$ and $T_{0}$, respectively, and $\alpha_{E}$ stands for the reduction coefficient under variational temperature, which can be determined as $0.3 \%$ for the concrete material [14].

Thus, based on the aforementioned uncertain conditions and according to the structural dynamic theory and finite element method, the structural undamped dynamic characteristic equation considering uncertain conditions can be written as follows:

$$
\left[\left(K_{s}(T, \theta)+K_{b c}(\alpha)\right)-\lambda_{i}\left(M_{s}+M_{b c}\right)\right] \varphi_{i}=0,
$$

where $K_{s}(T, \theta)$ stands for the global stiffness matrix of structural elements with the environmental temperature of $T$ and the structural damage severity of $\theta ; K_{b c}(\alpha)$ means the global stiffness matrix of boundary systems with the bearing damage severity of $\alpha ; M_{s}$ and $M_{b c}$ denote the global mass matrix of structural elements and boundary systems, respectively; and $\lambda_{i}$ and $\varphi_{i}$ are the $i$-th eigenvalue and eigenvector, respectively. Moreover, it needs to be pointed out that the effects of environmental temperature variations on the boundary systems have been ignored.

2.2. The Evaluation of the Factors. First of all, the factors have been studied to evaluate the influences on the modal parameters (e.g., natural frequencies and vertical modal shapes).

2.2.1. Structural Element Damage. To select one structural element randomly and introducing damage severity that ranges from 0 to $100 \%$, the increasing step size is determined as $1 \%$ to calculate the corresponding natural frequencies and modal shapes. Then, the first four-order natural frequencies are extracted and illustrated in Figure 2, and the max nodal displacement of each vertical modal shape is obtained and plotted in Figure 3. As shown in Figure 2, the damage occurring in the structural element will cause the decline of the frequencies, especially for the first- and fourth-order frequencies; the falling ranges are larger than others. And from the perspective of the vertical modal shapes, the element damage will cause the max nodal displacements of the first three-order modal shapes to enhance with different extents; meanwhile, the damage also causes some effects on the fourth modal shapes; however, the trend shows ascending first, then declines, and rises finally.

2.2.2. Structural Bearing Damage. To select the structural bearing in the left end, adopting the way of stiffness reduction to simulate different damage severities at the bearing. Then, the dynamic characteristics of the beam with the corresponding bearing damage are obtained, which can be seen in Figures 2 and 3. From Figure 2, it can be seen that the bearing damage has some negative effects on the natural frequencies, especially for the first two-order frequencies, 


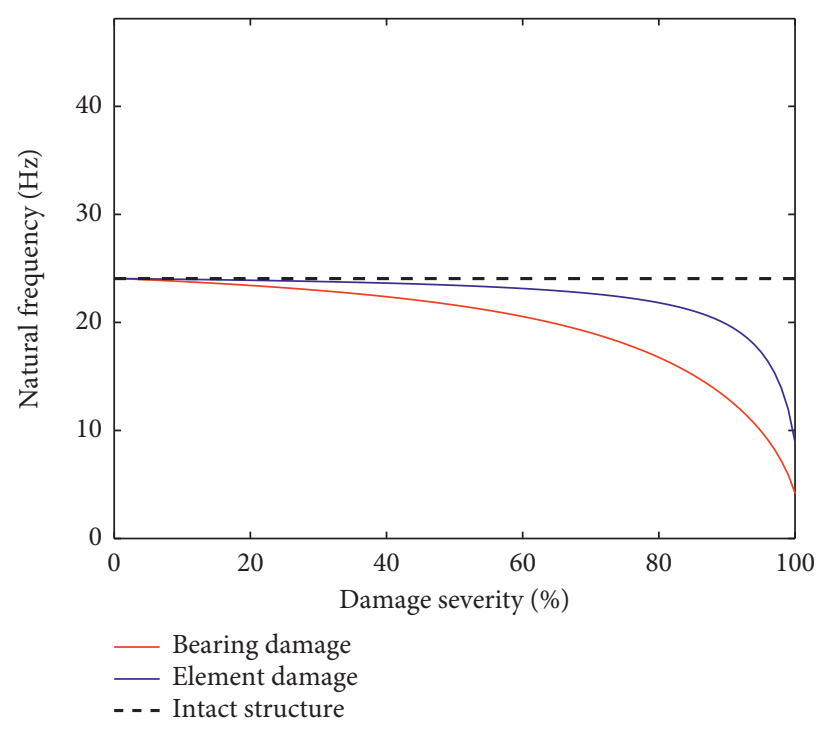

(a)

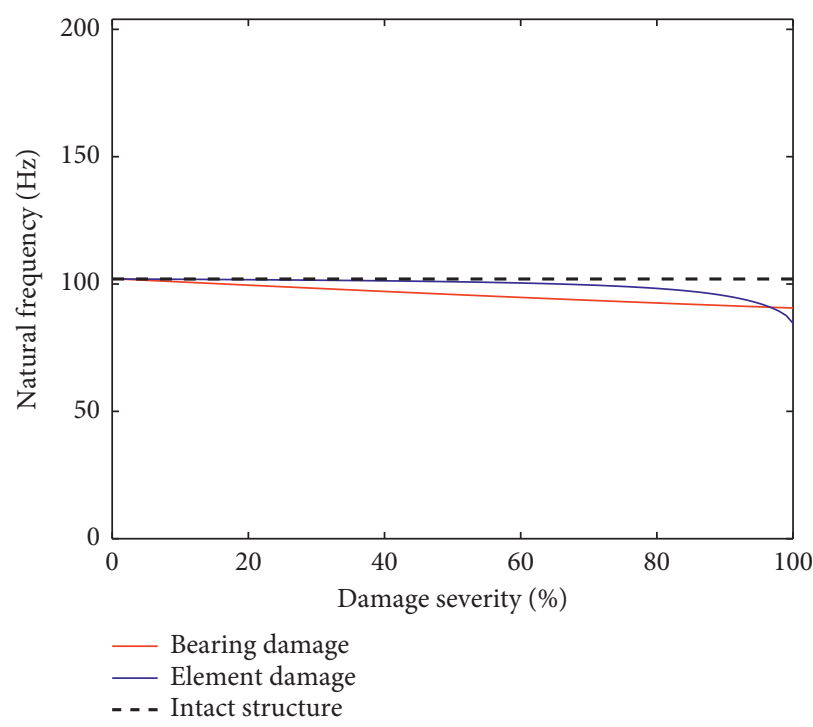

(c)

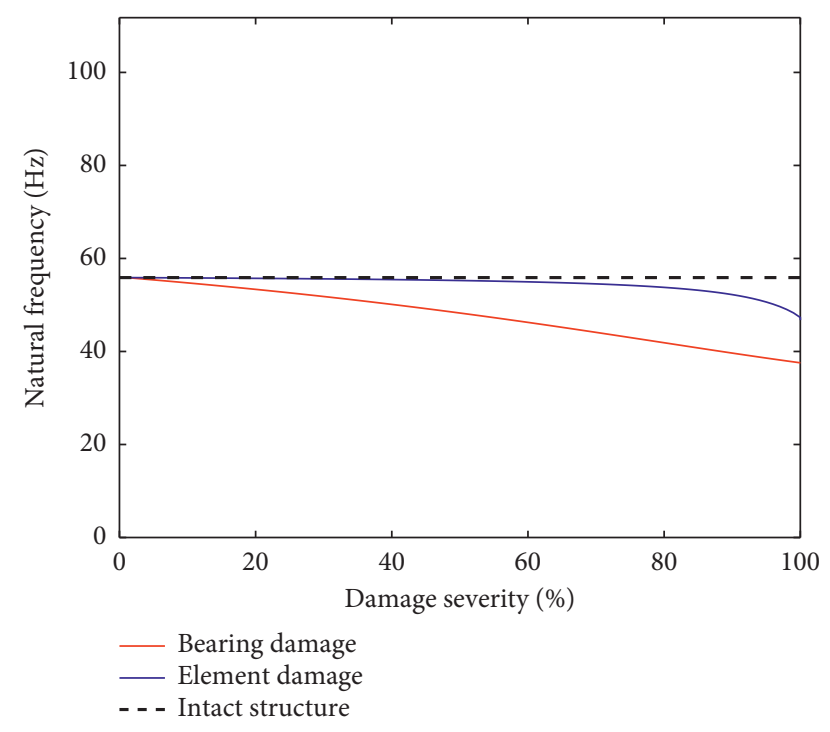

(b)

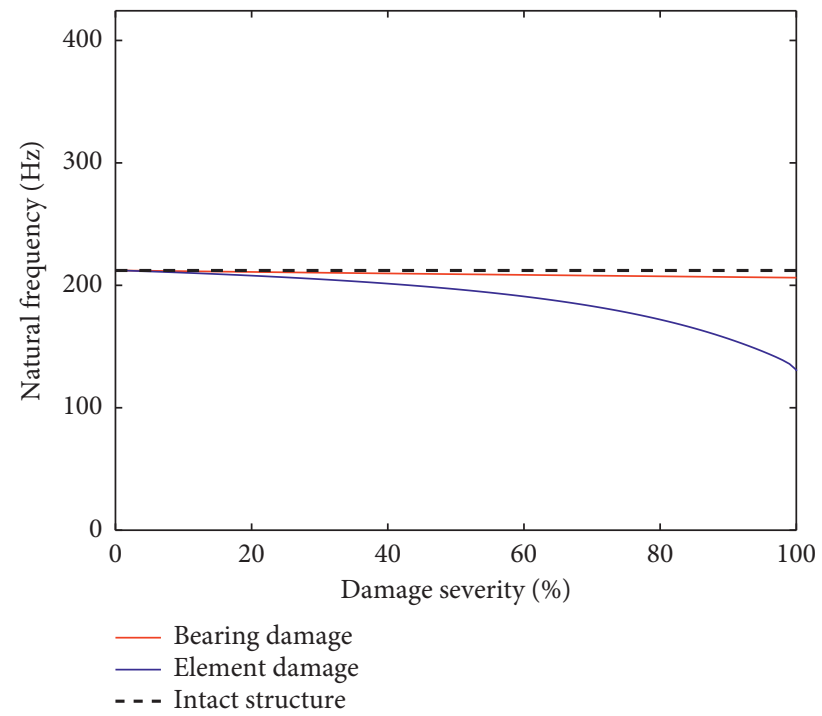

(d)

Figure 2: The (a) 1st, (b) 2nd, (c) 3rd, and (d) 4th change curves of frequencies under different damage severities in the structural element and bearing.

and the variations are more obvious than others. In terms of the max nodal displacements of each modal shape, for the third and fourth modal shapes, there is a positive correlation between the bearing damage and the max nodal displacement. However, the trend shows a decrease first and then a rise in the first modal shape, and for the second, the trend is converse, namely, increasing at first and then falling.

\subsubsection{Environmental Temperature Variations. Assuming} that the reference environmental temperature is $20^{\circ} \mathrm{C}$, the temperature change ranges between 20 and $60^{\circ} \mathrm{C}$, and the increasing step size is determined as $0.4^{\circ} \mathrm{C}$. To calculate the corresponding natural frequencies and modal shapes, the results are shown in Figures 4 and 5. As shown in Figure 4, the first two-order frequencies have shown a slight increase under the rising temperature, and when they achieve some specific values, they remain stable. However, the third and fourth frequencies have shown a sustained increase with the temperature variation. In addition, as shown in Figure 5, the rising temperature will lead to the decline of the max nodal displacements in the first and fourth modal shapes, reversely, an increase in the second modal shape. And the third modal shape will slightly go up and then fall steadily at a specific value.

2.3. The Summary of Evaluation. From the aforementioned analyses, one can conclude that the three factors will cause the fluctuation on the modal parameters to different extents, and the effects are uncertain which are difficult to propose a linear relationship. Meanwhile, although only the single factor rather than compound factors has been studied, the 


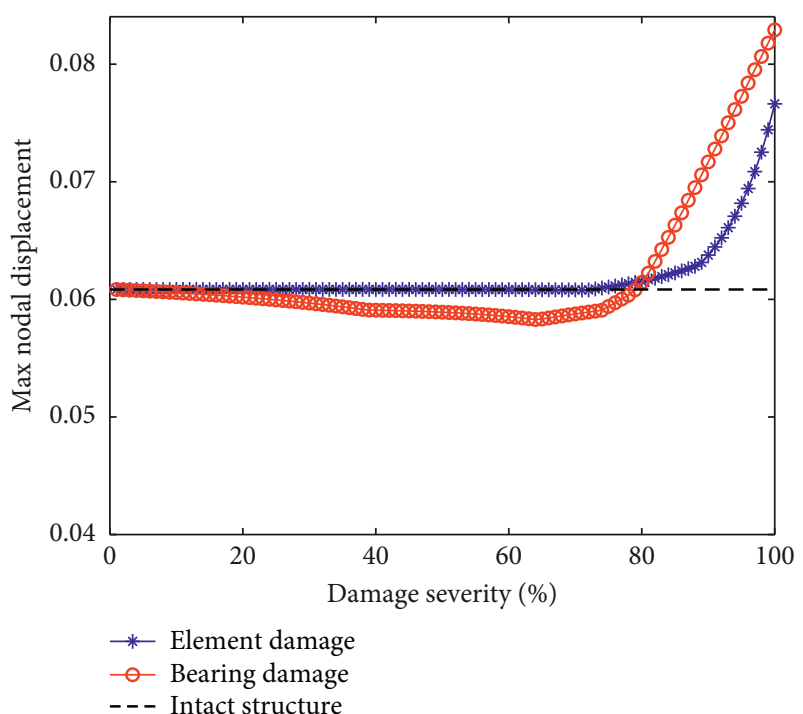

(a)

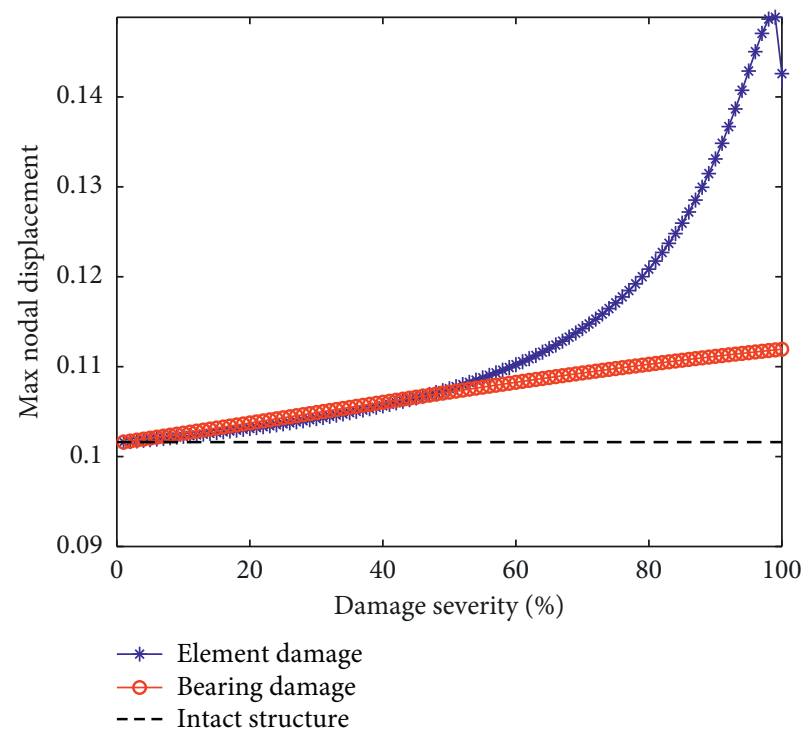

(c)

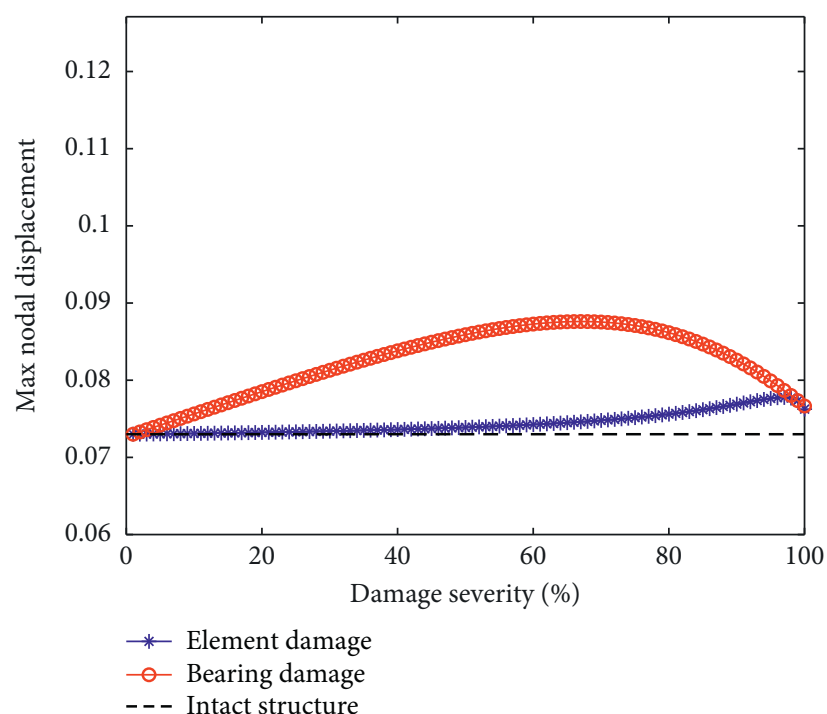

(b)

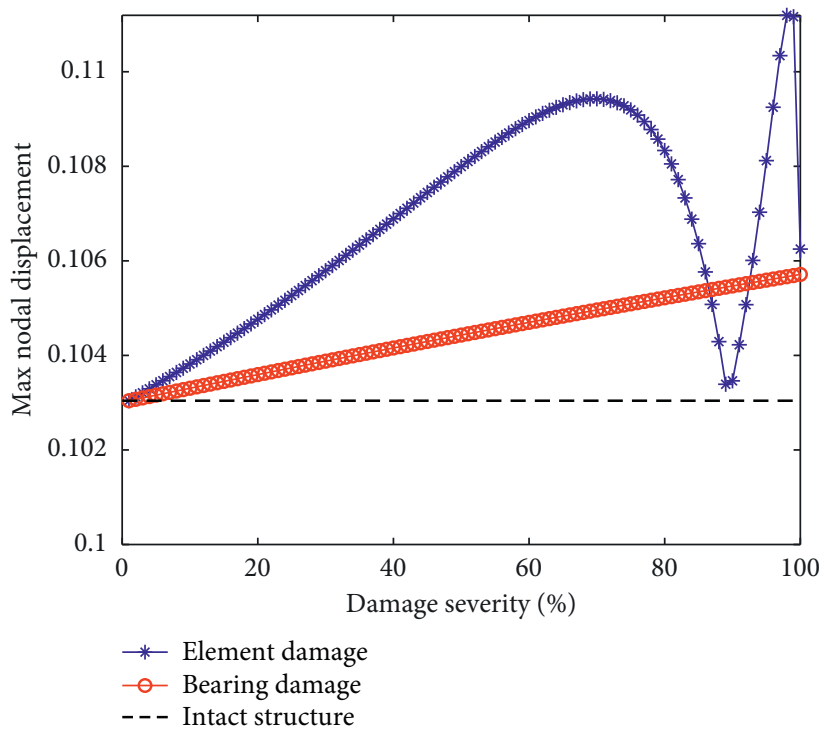

(d)

Figure 3: The (a) 1st, (b) 2nd, (c) 3rd, and (d) 4th change curves of max nodal displacement of each vertical modal shape under different damage severities in the structural element and bearing.

synergistic effects of multiple factors can be predicted to be more serious. As far as the practical situation is concerned, civil engineering structures are always surrounded by severe environmental conditions; this situation means the uncertain conditions are the main error origins of measured modal parameters; furthermore, they threaten the accuracy of the method of bearing damage detection based on modal parameters. Thereby, the uncertainties should be considered in the procedure of bearing damage detection.

\section{Bayesian Theory for Damage Detection}

3.1. The Basic Theory of Bayesian Damage Detection. Bayesian framework is a useful tool to consider the uncertainty from the probabilistic view. In the framework, the posterior probability distribution of the concerned variable can be expressed as follows:

$$
P(\beta \mid D, \tilde{M})=\frac{P(\beta \mid \tilde{M}) P(D \mid \beta, \tilde{M})}{P(D \mid \tilde{M})},
$$

where $\tilde{M}$ stands for the parameterized model; $D$ represents the measured data, e.g., natural frequencies and modal shapes; $\beta$ means the concerned variable; $P(D \mid \beta, \tilde{M})$ and $P(\beta \mid \tilde{M})$ are the likelihood function and the prior probability density function (PDF), respectively; and $P(D \mid \tilde{M})$ is a normalizing constant that is unrelated to the concerned variable.

Because the selected class of the model has an essential function on the success of model updating, furthermore, on the damage detection [34], assuming that the mass remains 


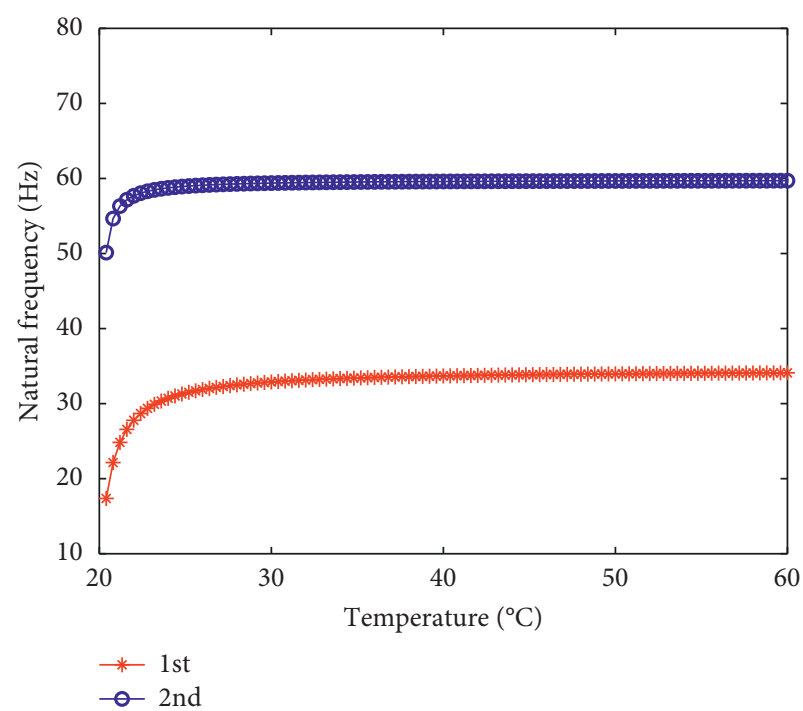

(a)

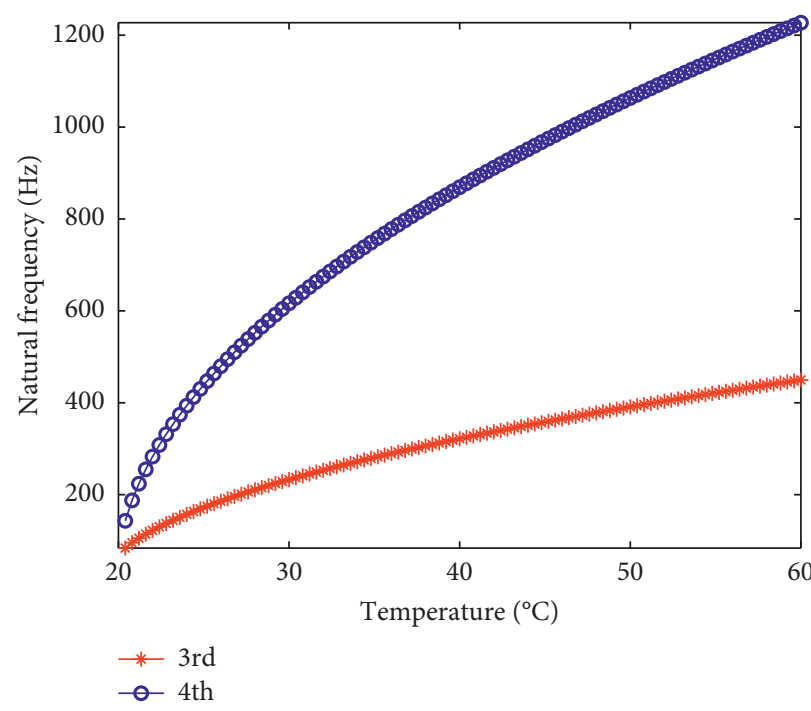

(b)

Figure 4: The (a) 1st, 2nd and (b) 3rd, 4th change curves of natural frequencies under different environmental temperatures.

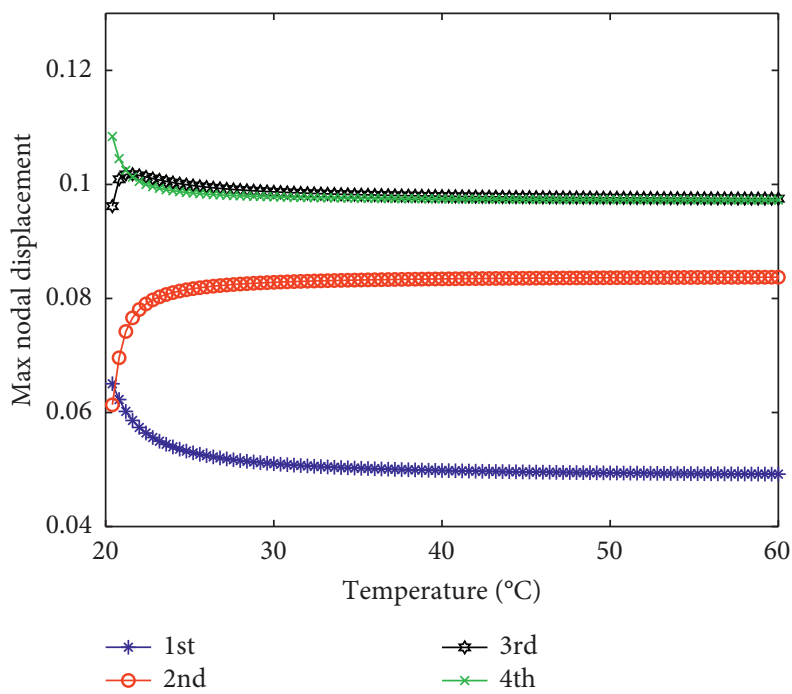

FiguRE 5: The change curves of max nodal displacement of each vertical modal shape under different environmental temperatures.

constant when the structure is damaged, the linear model considering multiple factors is adopted, which can be written as follows:

$$
\begin{aligned}
K & =K_{s}(T, \theta)+K_{b c}(\alpha), \\
K_{s}(T, \theta) & =\sum_{i=1}^{\text {nele }}\left(1-\theta_{i}\right) k_{i}^{T}, \quad 0 \leq \theta_{i} \leq 1, \\
K_{b c}(\alpha) & =\sum_{j=1}^{n b c}\left(1-\alpha_{j}\right) k_{j}^{b c}, \quad 0 \leq \alpha_{j} \leq 1,
\end{aligned}
$$

where $k_{i}^{T}$ means the element stiffness matrix corresponding to the temperature of $T$.

To consider the measurement and modelling errors and assuming that both errors follow the Gaussian distribution, the errors of each modal parameter can be evaluated as follows [35]:

$$
\begin{gathered}
\varepsilon_{f}=f_{i}-f_{i}(\beta) \sim N\left(0, \operatorname{cov}_{f_{i}}^{-1}\right), \\
\varepsilon_{\varphi}=\boldsymbol{\varphi}_{i}-\boldsymbol{\varphi}_{i}(\beta) \sim N\left(0, \operatorname{cov}_{\varphi_{i}}^{-1}\right),
\end{gathered}
$$

where $f_{i}(\beta)$ and $\varphi_{i}(\beta)$ are the $i$-th analytical natural frequency and modal shape, respectively; $f_{i}$ and $\varphi_{i}$ are the $i$-th experimental natural frequency and modal shape; $\beta$ means the concerned variable, and it can be defined as $\beta=[\theta, \alpha]$ to detect the damage of structural elements and bearings, or to be set as a single variable, such as $\beta=[\theta]$ for the damage of structural elements or $\beta=[\alpha]$ for the damage of structural bearings; and $\operatorname{cov}_{f_{i}}^{-1}$ and $\operatorname{cov}_{\varphi_{i}}^{-1}$ can be used to measure the uncertainty levels. Based on equations (10) and (11), the 
likelihood function of measured modal parameters can be deduced as follows:

$$
\begin{gathered}
P\left(f_{i} \mid \beta\right)=\left(\frac{\operatorname{cov}_{f_{i}}}{2 \pi}\right)^{\frac{1}{2}} \exp \left\{-\frac{\left(f_{i}-f_{i}(\beta)\right)^{2}}{2 \operatorname{cov}_{f_{i}}}\right\}, \\
P\left(\varphi_{i} \mid \beta\right)=\left(\frac{\operatorname{cov}_{\varphi_{i}}}{2 \pi}\right)^{\frac{1}{2}} \exp \left\{-\frac{\left(\boldsymbol{\varphi}_{i}-\boldsymbol{\varphi}_{i}(\beta)\right)^{T}\left(\boldsymbol{\varphi}_{i}-\varphi(\beta)\right)}{2 \operatorname{cov}_{\varphi i}}\right\} .
\end{gathered}
$$

Due to the independence of each modal test and assuming each order modal parameter is independent, there is no correlation between the modes. Thus, according to the first $n m$-order measured natural frequencies and modal shapes, the final form of the likelihood functions of $\beta$ can be obtained as follows:

$$
\begin{aligned}
& P(f \mid \beta)=\prod_{i=1}^{n m} P\left(f_{i} \mid \beta\right)=\left(\prod_{i=1}^{n m} \frac{\operatorname{cov}_{f i}}{2 \pi}\right)^{\frac{1}{2}} \exp \left(-\frac{1}{2} \sum_{i=1}^{n m} \frac{\left(f_{i}-f_{i}(\beta)\right)^{2}}{\operatorname{cov}_{f i}}\right) \\
& P(\boldsymbol{\varphi} \mid \beta)=\prod_{i=1}^{n m} P\left(\boldsymbol{\varphi}_{i} \mid \beta\right)=\left(\prod_{i=1}^{n m} \frac{\operatorname{cov}_{\varphi i}}{2 \pi}\right)^{\frac{1}{2}} \exp \left(-\frac{1}{2} \sum_{i=1}^{n m} \frac{\left(\boldsymbol{\varphi}_{i}-\boldsymbol{\varphi}_{i}(\beta)\right)^{T}\left(\boldsymbol{\varphi}_{i}-\boldsymbol{\varphi}(\beta)\right)}{\operatorname{cov}_{\varphi i}}\right) .
\end{aligned}
$$

Then, to submit equations (14) and (15) into equation (6), the posterior probability density function of $\beta$ can be expressed as follows:

$$
\begin{aligned}
& P(\beta \mid D, \tilde{M})=c^{-1} P(f \mid \beta) P(\boldsymbol{\varphi} \mid \beta) \\
& =c^{-1}\left(\prod_{i=1}^{n m} \frac{\operatorname{cov}_{f_{i}}}{2 \pi}\right)^{1 / 2}\left(\prod_{i=1}^{n m} \frac{\operatorname{cov}_{\varphi_{i}}}{2 \pi}\right)^{1 / 2} \\
& \exp \left\{-\frac{1}{2} \sum_{i=1}^{n m}\left[\frac{\left(f_{i}-f_{i}(\beta)\right)^{2}}{\operatorname{cov}_{f_{i}}}+\frac{\left(\boldsymbol{\varphi}_{i}-\boldsymbol{\varphi}_{i}(\beta)\right)^{T}\left(\boldsymbol{\varphi}_{i}-\boldsymbol{\varphi}(\beta)\right)}{\operatorname{cov}_{\boldsymbol{\varphi}_{i}}}\right]\right\},
\end{aligned}
$$

where $c^{-1}$ means a constant number. According to the maximum a posteriori (MAP) principle, optimal $\beta$ can be obtained by maximizing the posterior probability density function, namely, minimizing the exponential part of equation (16). However, due to the high dimensions of $\beta$, it is difficult to calculate; in order to solve this problem, the Monte Carlo Markov Chain (MCMC) method is adopted in this article.

3.2. The Metropolis-Hastings Sampling Method. The Metropolis-Hastings (HM) sampling method, as a popular way to obtain Markov chain, has been widely used in the MCMC simulation [36]. The main steps of the HM sampling method can be summarized as follows:

(1) To generate the initial sample $x^{t=0}$ randomly, then $t=t+1$, and generate candidate sample $x^{t}$ according to the proposal distribution $\gamma$.
(2) To calculate the ratio of two PDFs $\eta$ based on the equation as follows:

$$
\eta=\frac{P\left(x^{t-1}\right) \gamma\left(x^{t} \mid x^{t-1}\right)}{P\left(x^{t}\right) \gamma\left(x^{t-1} \mid x^{t}\right)}=\frac{P\left(x^{t-1}\right)}{P\left(x^{t}\right)} .
$$

(3) To judge the candidate sample referring to the Metropolis principle, namely, if $\eta \geq 1$, then $x^{t}=x^{t}, t=t+1$, to generate the candidate sample again. When $\eta<1$, to generate a random number $\mu$, then to judge whether $\eta$ is greater than or equal to $\mu$, if yes, the candidate sample sample is accepted; but, if $\eta<\mu$, the candidate sample is rejected, $x^{t}=x^{t-1}, t=$ $t+1$. After the judgment, generate the candidate sample again.

(4) When $t \longrightarrow+\infty$, the Markov chain has been formed.

3.3. Matrix Perturbation Method. Due to the iterative calculation of Bayesian damage detection, it is noticeable that the computational cost of the calculation of analytical modal parameters in the updating process is very expensive. Meanwhile, the accurate finite element model of the structure is very demanding in every iteration. These requirements make the detection process face a series of challenges. Thereby, researchers proposed the surrogate model to replace the complicated finite element model, which can provide good computation efficiency in the detection process [20].

In this paper, the matrix perturbation method is introduced, according to equation (5), and to consider the variations in the structural global stiffness and mass matrix, the $1^{\text {st }}$-order perturbation formulae for frequencies and modal shapes can be given directly as follows: 


$$
\left\{\begin{array}{l}
\lambda_{i}^{p 1}=\left[\boldsymbol{\varphi}_{i}^{0}\right]^{T}\left(K^{1}-\lambda_{i}^{0} M^{1}\right) \boldsymbol{\varphi}_{i}^{0}, \\
\boldsymbol{\varphi}_{i}^{p 1}=\sum_{k=1, \neq i}^{n m}\left[\frac{\left[\boldsymbol{\varphi}_{k}^{0}\right]^{T}\left(K^{1}-\lambda_{i}^{0} M^{1}\right) \boldsymbol{\varphi}_{i}^{0}}{\lambda_{i}^{0}-\lambda_{k}^{0}}\right] \boldsymbol{\varphi}_{k}^{0}-\frac{1}{2}\left(\left[\boldsymbol{\varphi}_{i}^{0}\right]^{T} M^{1} \boldsymbol{\varphi}_{i}^{0}\right) \boldsymbol{\varphi}_{i}^{0} .
\end{array}\right.
$$

And the $2^{\text {nd }}$-order perturbation formulae can be expressed as follows:

$$
\left\{\begin{array}{l}
\lambda_{i}^{p 2}=\left[\boldsymbol{\varphi}_{i}^{0}\right]^{T}\left(K^{1} \boldsymbol{\varphi}_{i}^{p 1}-\lambda_{i}^{0} M^{1} \boldsymbol{\varphi}_{i}^{p 1}-\lambda_{i}^{p 1} M^{0} \boldsymbol{\varphi}_{i}^{p 1}-\lambda_{i}^{p 1} M^{1} \boldsymbol{\varphi}_{i}^{0}\right), \\
\boldsymbol{\varphi}_{i}^{p 2}=\sum_{k=1, \neq i}^{n m}\left[\frac{\left[\boldsymbol{\varphi}_{k}^{0}\right]^{T}\left(K^{1} \boldsymbol{\varphi}_{i}^{p 1}-\lambda_{i}^{0} M^{1} \boldsymbol{\varphi}_{i}^{p 1}-\lambda_{i}^{1} M^{0} \boldsymbol{\varphi}_{i}^{p 1}-\lambda_{i}^{1} M^{1} \boldsymbol{\varphi}_{i}^{0}\right)}{\lambda_{i}^{0}-\lambda_{k}^{0}}\right] \boldsymbol{\varphi}_{k}^{0}, \\
-\frac{1}{2}\left(\left[\boldsymbol{\varphi}_{k}^{0}\right]^{T} M^{1} \boldsymbol{\varphi}_{i}^{p 1}+\left[\boldsymbol{\varphi}_{i}^{p 1}\right]^{T} M^{0} \boldsymbol{\varphi}_{i}^{p 1}+\left[\boldsymbol{\varphi}_{i}^{p 1}\right]^{T} M^{1} \boldsymbol{\varphi}_{i}^{0}\right) \boldsymbol{\varphi}_{i}^{0},
\end{array}\right.
$$

where $\lambda_{i}^{p 1}$ and $\lambda_{i}^{p 2}$ represent the $1^{\text {st }}$ - and $2^{\text {nd }}$-order perturbation values of the $i$-th eigenvalue, respectively; $\varphi_{i}^{p 1}$ and $\varphi_{i}^{p 2}$ stand for the $1^{\text {st }}$ - and $2^{\text {nd }}$-order perturbation values of the $i$-th eigenvector, respectively; $\lambda_{i}^{0}$ and $\varphi_{i}^{0}$ denote the $i$-th original eigenvalue and eigenvector, respectively; $K^{1}$ and $M^{1}$ mean the $1^{\text {st }}$ order perturbation values of the stiffness and mass matrices, respectively; and $M^{0}$ is the original structural mass matrix. Therefore, the $i$-th eigenvalue and eigenvector after the perturbation can be calculated as follows:

$$
\left\{\begin{array}{l}
\widehat{\lambda}_{i}=\lambda_{i}^{0}+\varepsilon \lambda_{i}^{p 1}+\varepsilon^{2} \lambda_{i}^{p 2}+\mathrm{O}\left(\varepsilon^{3}\right), \\
\widehat{\varphi}_{i}=\varphi_{i}^{0}+\varepsilon \boldsymbol{\varphi}_{i}^{p 1}+\varepsilon^{2} \boldsymbol{\varphi}_{i}^{p 2}+\mathrm{O}\left(\varepsilon^{3}\right),
\end{array}\right.
$$

where $\varepsilon$ means the perturbation coefficient. The perturbation method only needs the modal parameters of the intact structure to calculate the modal parameters after the physical properties change, which can avoid the repetitive finite element modelling and cut down the computational cost.

3.4. Damage Identification Method. The main steps of the proposed damage identification method can be drawn as follows:

(1) Firstly, to construct the finite element model of the structure considering the environmental temperature variations and structural element and bearing damage, as well as random noise, and then its stiffness and mass matrices, eigenvalues, and eigenvectors are obtained

(2) Using stiffness and mass matrices, eigenvalues, and eigenvectors to establish the perturbation model of the structure

(3) Taking the perturbation model and Bayesian framework to detect the damage of structural elements and bearings

The flowchart is shown in Figure 6.

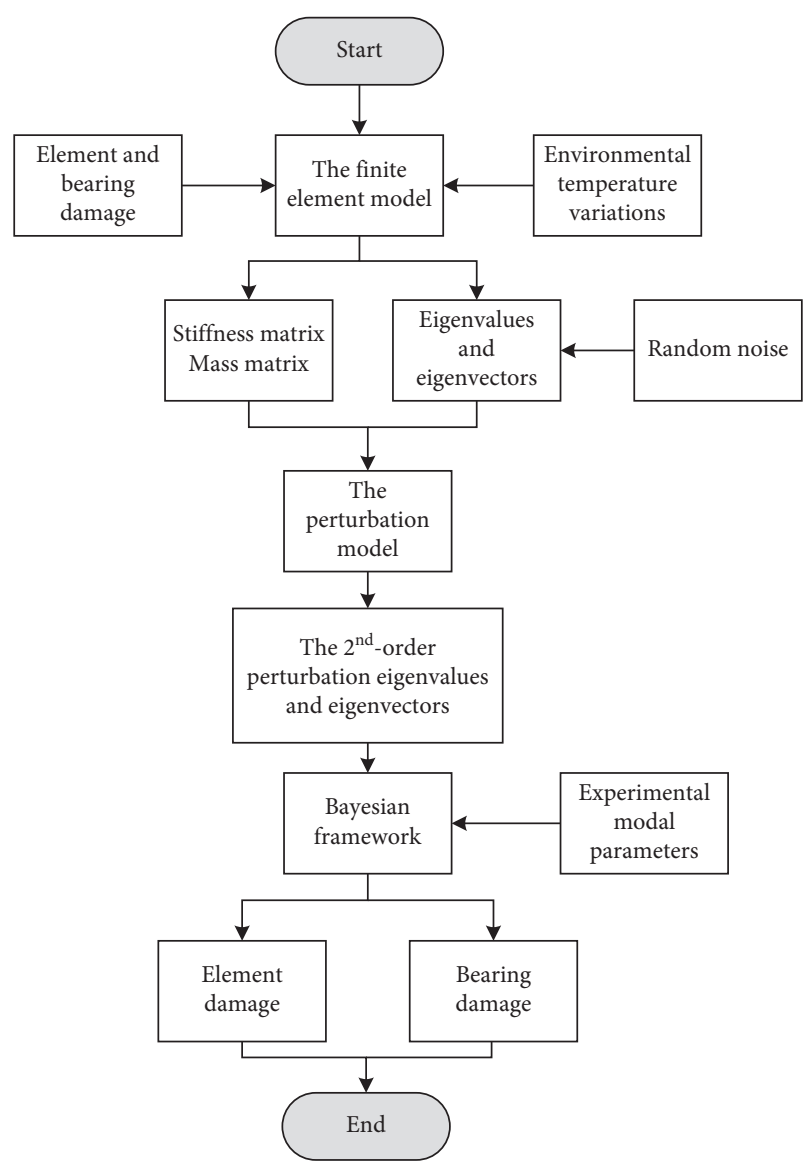

FIGURE 6: The flowchart of the damage identification method.

\section{Example Studies}

\subsection{Numerical Example}

4.1.1. Example Introduction and Damage Cases. In this section, as shown in Figure 7, an 8-span concrete continuous beam structure with 9 vertical bearings and 48 elements has been used to verify the proposed bearing damage detection method. The beam structure is with Young's modulus of $3.0 \times 10^{10} \mathrm{~Pa}$, the mass density of $2360 \mathrm{~kg} / \mathrm{m}^{3}$, Poisson's ratio of 0.15 , the inertia moment of $8.64 \times 10^{-5} \mathrm{~m}^{4}$, and the crosssectional area of $0.072 \mathrm{~m}^{2}$; and for each element, its length is $0.25 \mathrm{~m}$. In addition, the structural element is modelled by the 6-DOF beam element, and the bearing is simulated by the spring element of $6.0 \times 10^{6} \mathrm{~N} / \mathrm{m}$.

There are seven damage cases that are preset to validate the feasibility of the proposed damage detection method, which are listed in Table 1. In the practical situation, sometimes, the damage occurs in the elements and bearings simultaneously; thus, the preset cases can not only study the single type of damage, e.g., structural element or bearing, but also consider the multiple types of damage. As listed in Table 1, case 1 stands for the situations of element damage that has occurred in the two ends; cases $2-4$ are utilized to consider the damage emerged in elements and bearings at the same spatial location simultaneously; and cases 5-7 mean the damage of the element and bearing rising in 


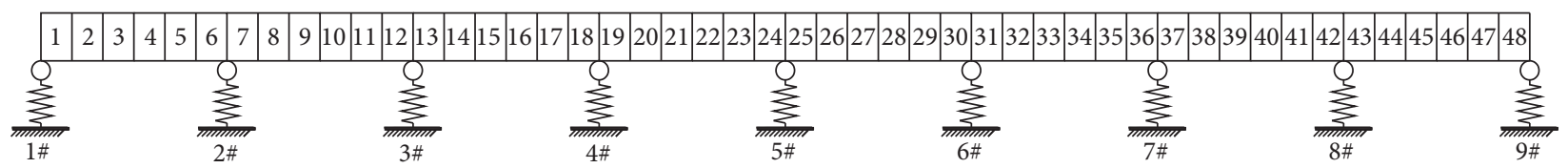

Figure 7: The 8-span continuous beam structure.

TABle 1: The damage cases of the continuous beam structure.

\begin{tabular}{|c|c|c|c|c|c|}
\hline $\begin{array}{l}\text { Noise level } \\
(\%)\end{array}$ & $\begin{array}{c}\text { Temperature variation (reference } \\
\left.\text { temperature is } 0\left({ }^{\circ} \mathrm{C}\right)\right)\end{array}$ & Case & $\begin{array}{c}\text { Damage severity @ element } \\
\text { number }\end{array}$ & $\begin{array}{c}\text { Damage severity @ bearing } \\
\text { number }\end{array}$ & $\begin{array}{l}\text { Detection } \\
\text { goal }\end{array}$ \\
\hline \multirow{7}{*}{3} & \multirow{7}{*}{20} & 1 & $\begin{array}{l}50 \% @ 1 \\
30 \% @ 48\end{array}$ & I & E \\
\hline & & 2 & \multirow{4}{*}{ 50\%@ @ 1} & \multirow{4}{*}{ 30\% @1\# } & $\mathrm{E}$ \\
\hline & & 3 & & & E \\
\hline & & 4 & & & $\mathrm{~B}$ and $\mathrm{E}$ \\
\hline & & 5 & & & B \\
\hline & & 6 & \multirow[t]{2}{*}{$50 \% @ 26$} & \multirow[t]{2}{*}{ 30\%@1\# } & $\mathrm{E}$ \\
\hline & & 7 & & & $\mathrm{~B}$ and $\mathrm{E}$ \\
\hline
\end{tabular}

Note: $\mathrm{E}$ and $\mathrm{B}$ denote the element damage and bearing damage, respectively.

different spatial locations, respectively. Moreover, the environmental factors such as temperature variation and random noise effects are both considered. The temperature variation can be simulated according to equation (4), and the random noise can be simulated as follows [37]:

$$
\left[f_{i}^{k}, \varphi_{i}^{k}\right]=\left[f_{i}, \varphi_{i}\right] \cdot(1+\sigma \mathrm{rand})
$$

where $\left[f_{i}, \varphi_{i}\right]$ and $\left[f_{i}^{k}, \varphi_{i}^{k}\right]$ mean the $i$-th noise-free and contaminated natural frequencies and modal shapes, respectively; $\sigma$ stands for the noise pollution level [38-40]; and rand is a random number that ranges from -1 to 1 .

4.1.2. Damage Identification and Results' Discussion. Aiming to every damage case, the modal test number is 50, and the first five-order natural frequencies and modal shapes are adopted; and the iterative number is determined as 5000 for case 1 and 10,000 for cases 2-7. Meanwhile, another method in the paper [13] is also adopted to make a comparison, namely, the identification method using optimization algorithm and sensitivity analysis (OASA), which can make a comparison with the proposed method. As far as OASA is concerned, herein, some parameters of CMF-IWO algorithm except for the iterative number and population size are the same as in [13]. The iterative number is defined as 500 for case 1 and 1000 for cases 2-7, and the population size is defined as 100 for each damage case; for every damage case, to run the procedure for 7 times, the average identified results are extracted. The Markov chains and histograms of the proposed method are extracted and shown in Figures 8-14, and the damage detection results of two methods are illustrated in Table 2.

As shown in Figure 8, the proposed method shows a good ability to detect the damage of structural elements, the max error is 3.04\%, and two Markov chains of case 1 always remain nonstationary; there is no smooth segment in them; and the histograms illustrate that the mean values of element and bearing damage parameters obey the preset values.
And in Figures 9 and 10, although there is another damage situation that has some negative effects on the detection process, the bearing and element damage can be measured independently. And the max errors are $6.46 \%$ that emerge in case 2 . Considering the practical situation of bridge engineering, the finding means that the proposed method is possible to apply in the practical application of detecting the bearings or structural elements individually.

Meanwhile, Figure 11 shows that the method can detect the damage of the bearing and structural element simultaneously. However, the Markov chain of the structural element indicates some fluctuations, especially in the early stage. This situation represents that researchers should pay more attention to study the scenario similar to case 4 in the future.

In terms of Figures 12 and 13, the same conclusion as Figure 8 can be drawn. And the max error that occurred in case 6 is $3.32 \%$.

From the perspective of Figure 14, the Markov chain of bearing damage parameter is very stable, but another one fluctuates intensely, which can be owed to the selection of the variance of assuming proposal distribution. Thus, how to determine a suitable variance is a key factor to identify the damage of the element accurately when bearing and element damage exist simultaneously.

Furthermore, from Table 2, although the OASA method can accurately tackle the single structural element damage cases or single bearing damage cases, e.g., cases 2-3 and 5-6, however, regarding the multiple-damage case, namely, structural element and bearing damage, compared to the proposed method, the identified results of the OASA method are worse. For case 1, the detected damage extents of the structural element and bearing have been exchanged, which is owed to the negative effect of uncertainties or the poor global optimization ability of the optimization algorithm. And for cases 4 and 7, the identified damage severities are not consistent with the preset values. 

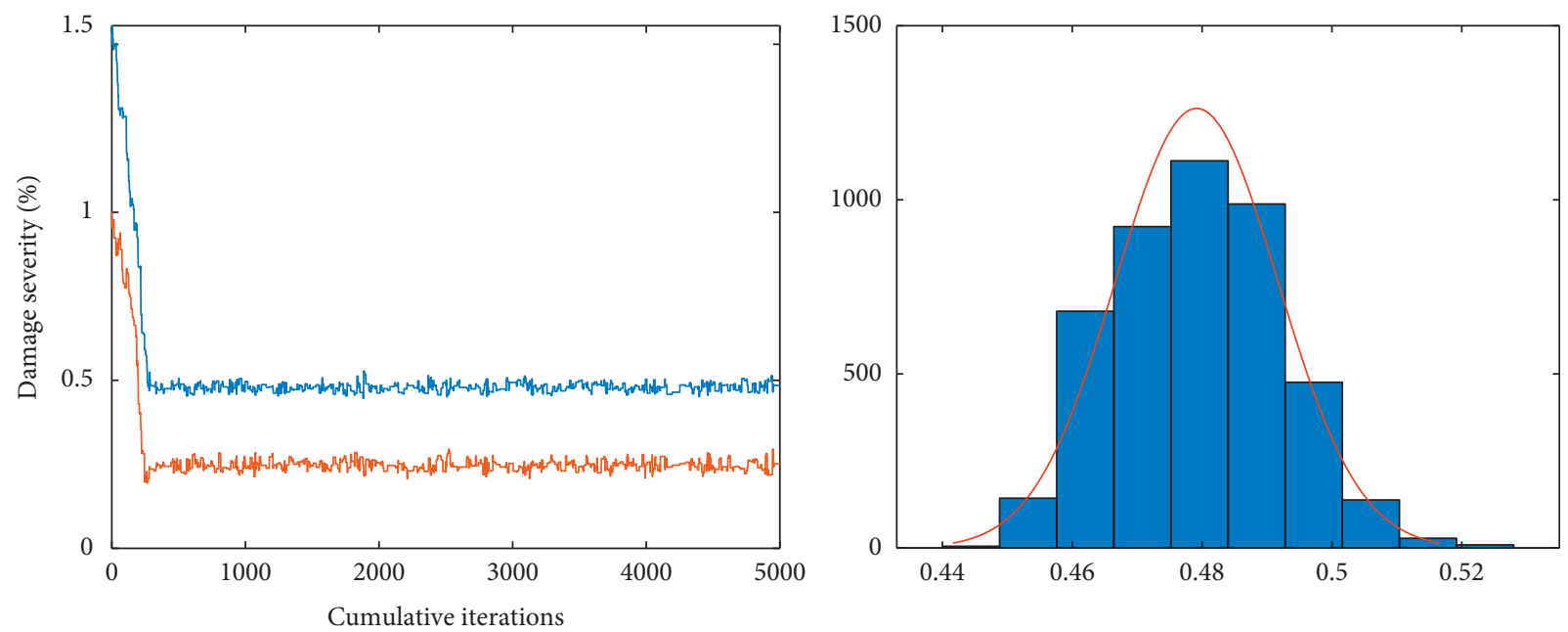

Element 1

Element 1

Element 48

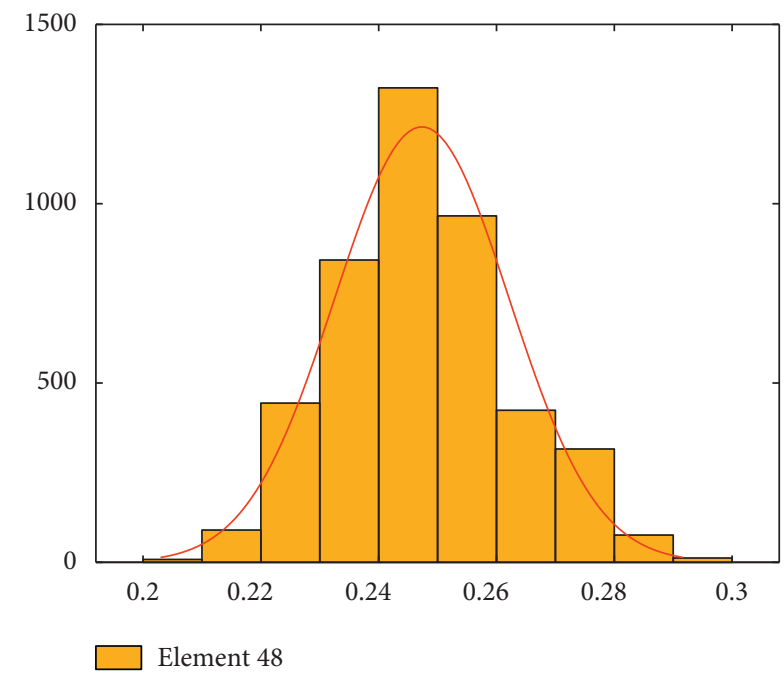

Figure 8: The Markov chains and histograms of damage case 1.

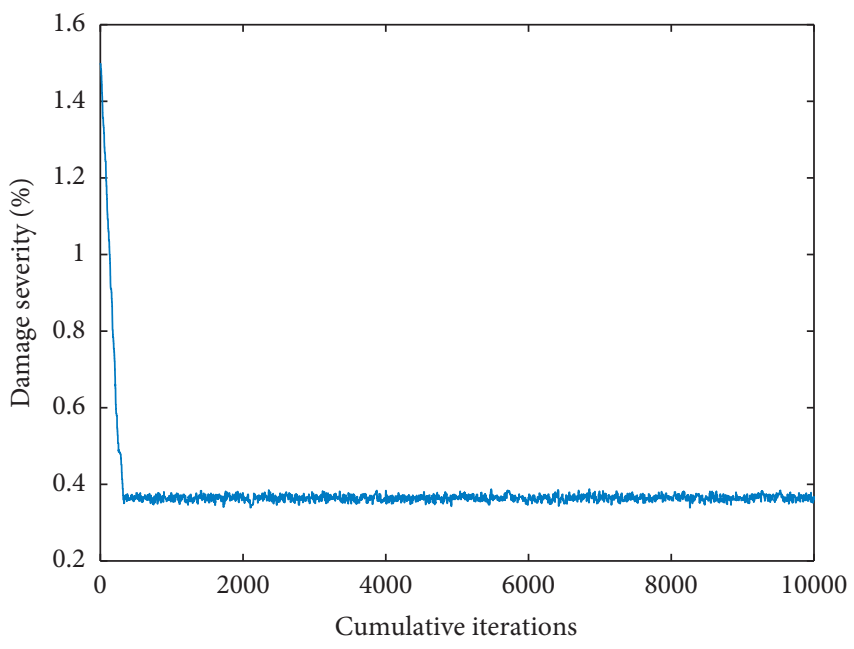

__ Bearing 1

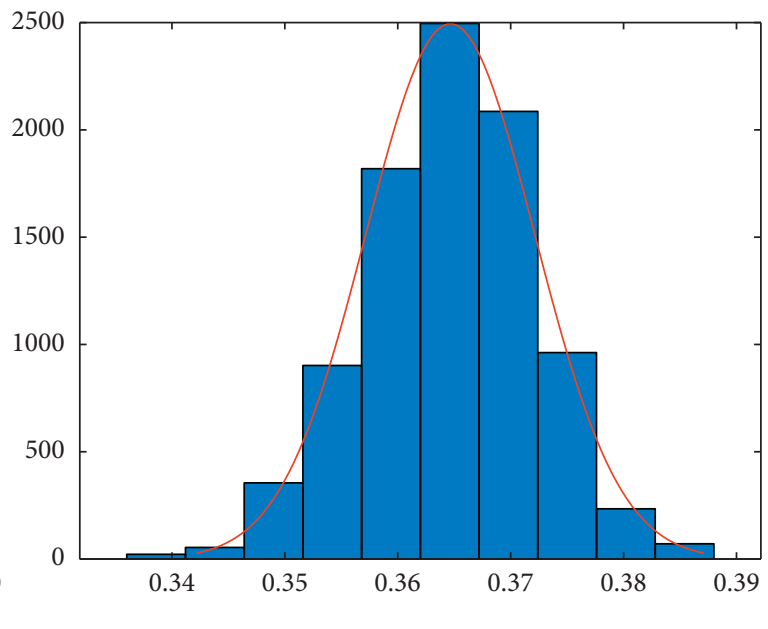

Bearing 1\#

Figure 9: The Markov chains and histograms of damage case 2. 


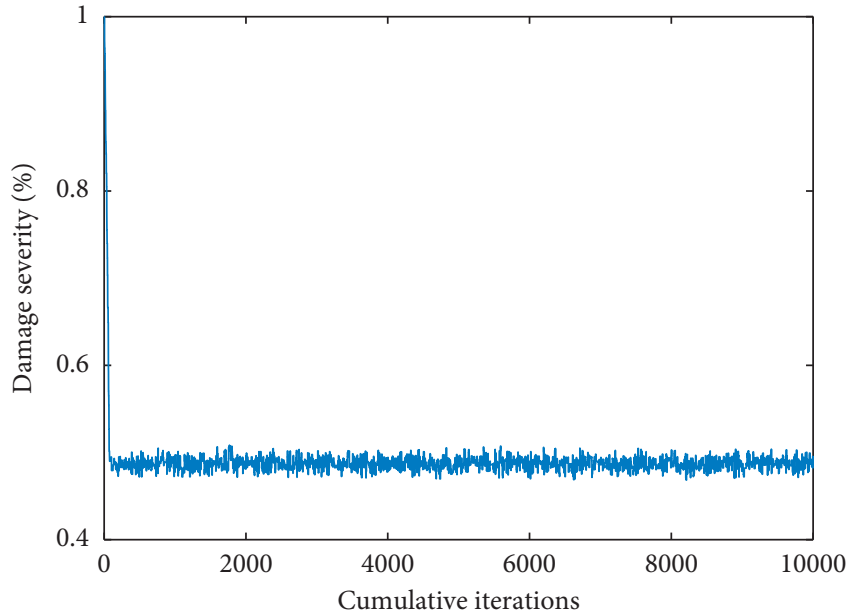

- Element 1

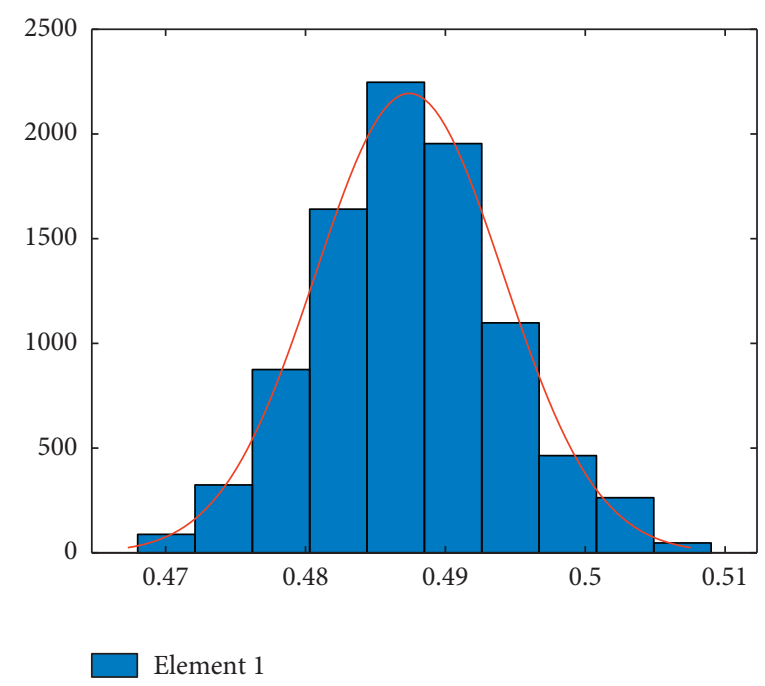

Element 1

FIgURE 10: The Markov chains and histograms of damage case 3.
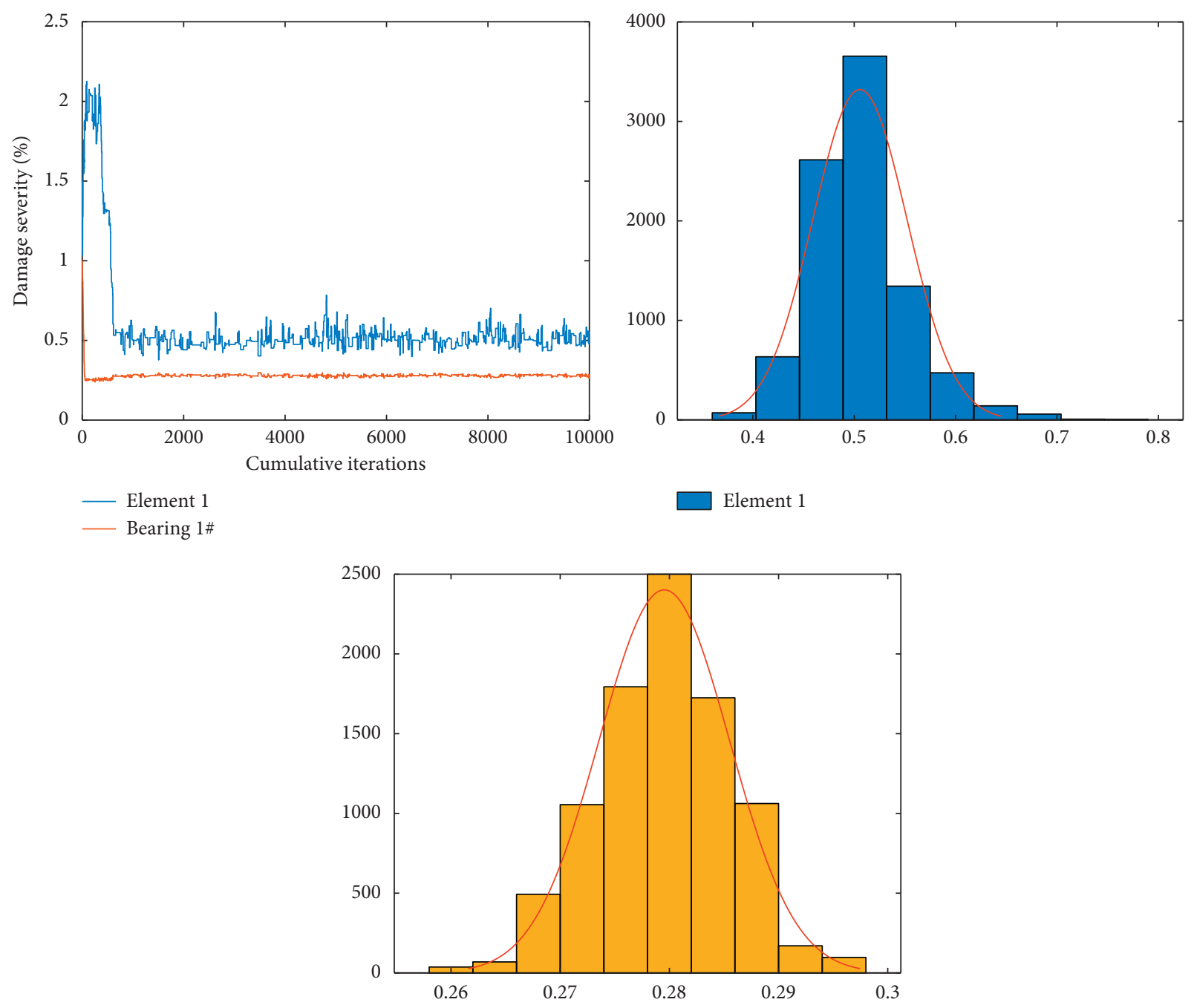

Bearing 1\#

Figure 11: The Markov chains and histograms of damage case 4. 

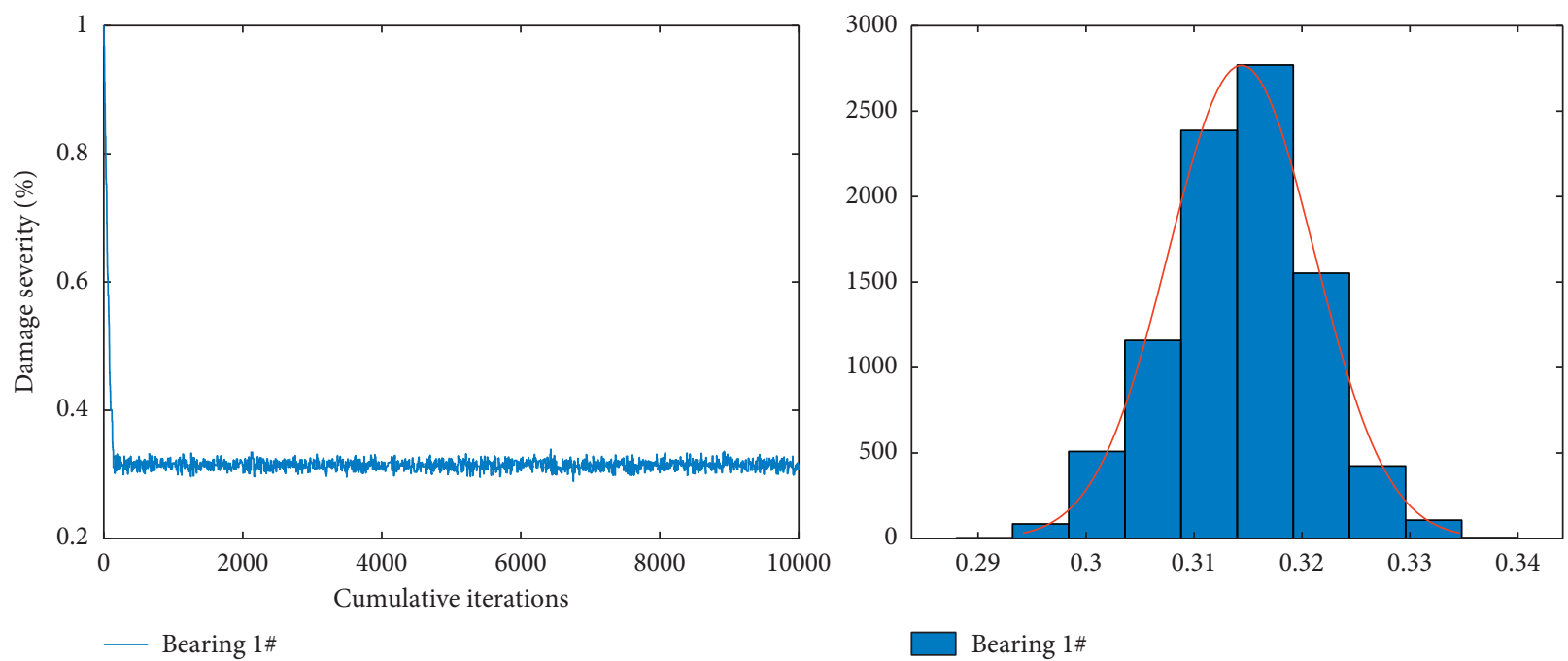

FIgURE 12: The Markov chains and histograms of damage case 5.
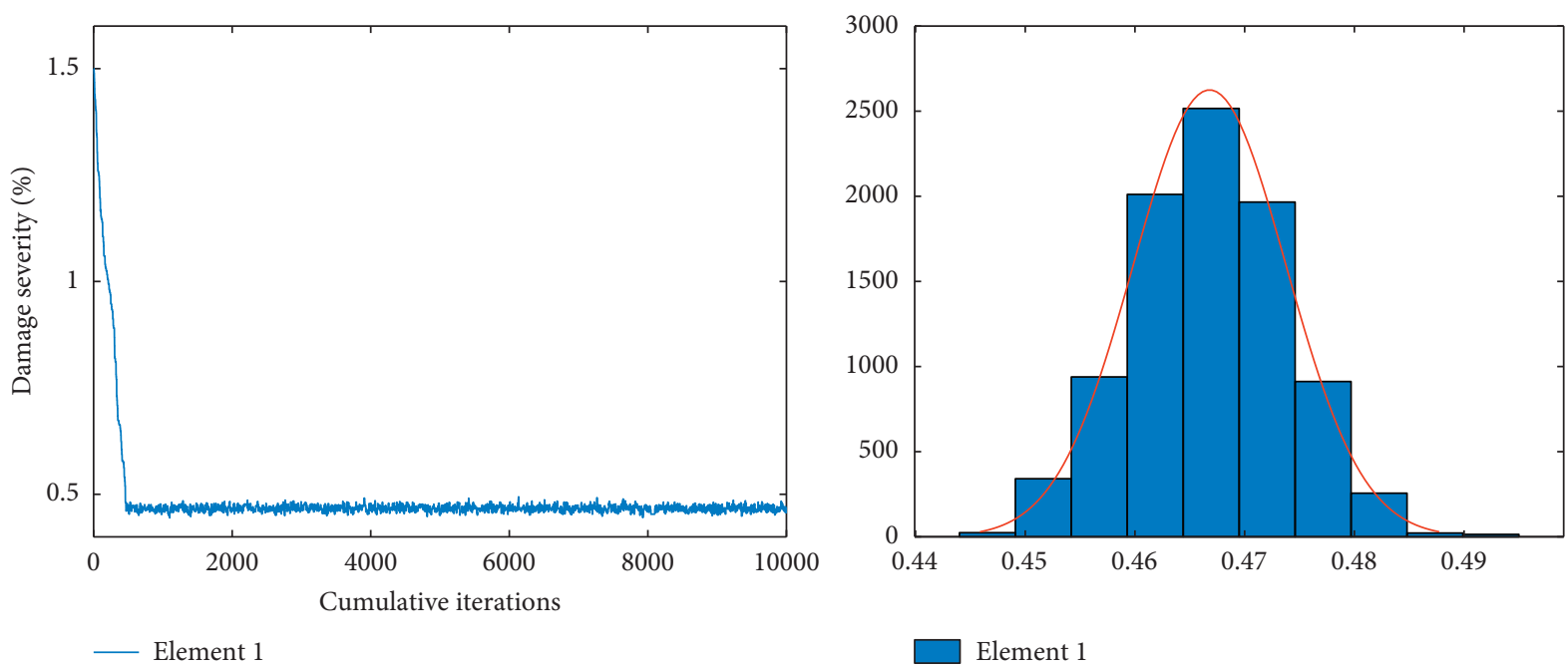

FIgURE 13: The Markov chains and histograms of damage case 6.

To summarize, from the aforementioned analyses and discussions, one can conclude that based on the proposed method, it has good feasibility to detect the structural bearing damage and structural element damage independently and even the two types of damage simultaneously. At the same time, the proposed method can overcome the distraction of uncertainties such as temperature variations and random noise, which shows good potential in the practical application.

\subsection{Engineering Example}

4.2.1. The Introduction of the Example. In order to further verify the practicability of the proposed method, in this section, a practical engineering of I-40 steel-concrete bridge has been exploited. This bridge is sited in Albuquerque, New Mexico, USA, and the related studies have become the classical cases in the field of structural health monitoring. A vibration test was carried out to collect the dynamic characteristics [41], and the obtained data have been widely used to verify the diverse damage detection approach. Figure 15 illustrates the overall view and experimental setup of the bridge.

In the middle span of the north plate girder of the bridge, there are four damage cases which have been introduced, which can be seen in Figure 16. After the introduction, the modal test was conducted for every damage case, and for D-1 to D-4, the corresponding ambient temperatures and approximate damage severities were recorded, which are $\left(15.5^{\circ} \mathrm{C}, 5 \%\right),\left(28.9^{\circ} \mathrm{C}, 10 \%\right),\left(26.1^{\circ} \mathrm{C}, 32 \%\right)$, and $\left(20.0^{\circ} \mathrm{C}\right.$, $92 \%)$, respectively.

Referring to the report of the modal experiment and collected modal characteristics, the finite element model has been programmed using MATLAB $[22,32,42]$, which is described in Figure 17. In this model, the concrete deck and the web of the plate girder are both simulated by the 4-node shell element, and other components, such as the flanges of 

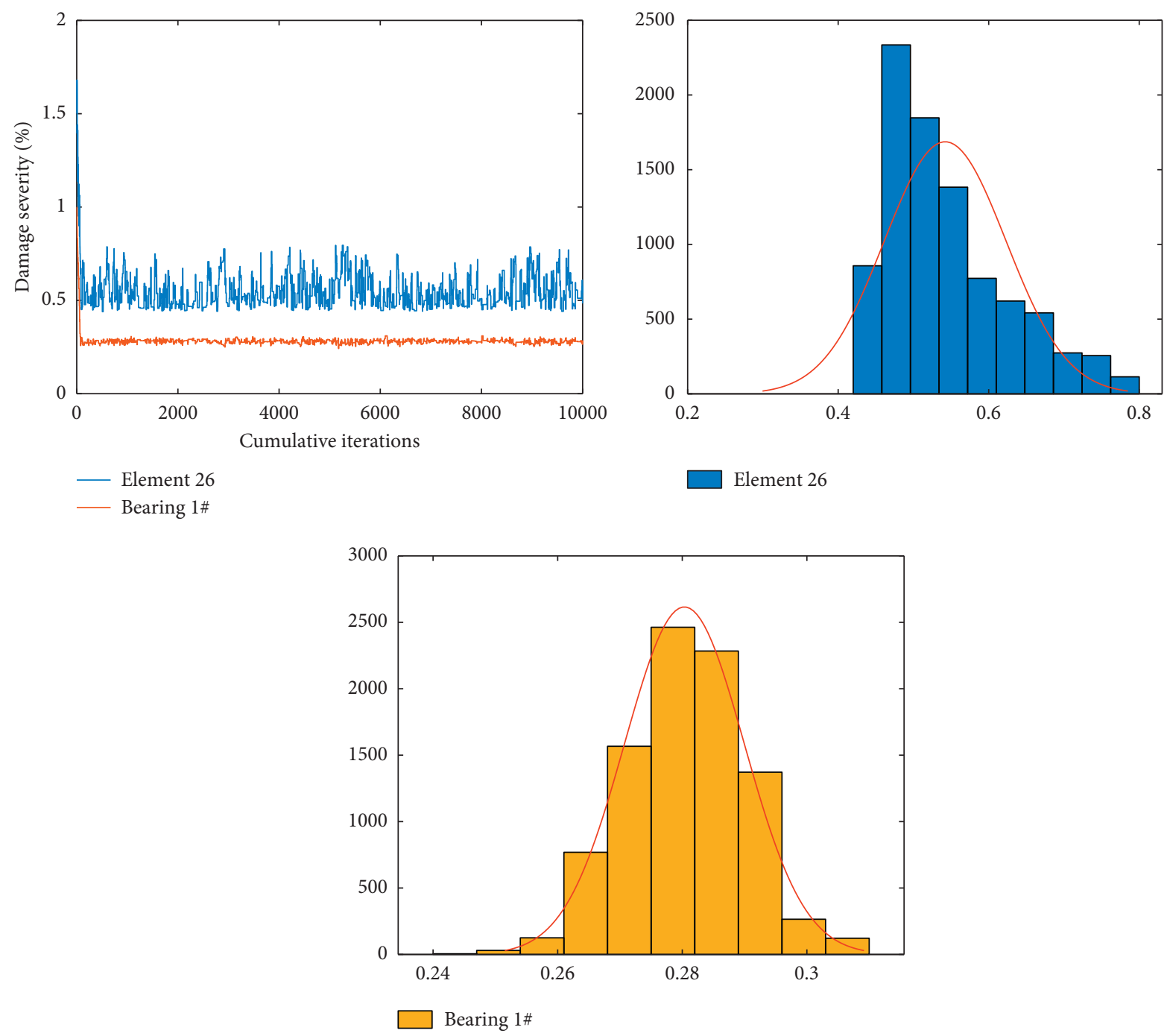

FIgURE 14: The Markov chains and histograms of damage case 7.

TABLE 2: The damage identification results of the continuous beam structure.

\begin{tabular}{|c|c|c|c|}
\hline Case & Preset damage severity & Identified damage severity (Bayesian method) & Identified damage severity (OASA method) \\
\hline \multirow{2}{*}{1} & $50 \% @ 1$ & 46.96\%@1 & 33.53\%@1 \\
\hline & 30\%@48 & 27.54\%@48 & 46.51\%@48 \\
\hline 2 & 30\%@1\# & 36.46\%@1\# & $29.83 \% @ 1 \#$ \\
\hline 3 & 50\%@1 & 48.74\%@1 & 49.96\%@1 \\
\hline \multirow{2}{*}{4} & 30\%@1\# & $27.80 \% @ 1 \#$ & 26.95\%@1\# \\
\hline & 50\%@1 & $50.68 \% @ 1$ & 39.62\%@1 \\
\hline 5 & 30\%@1\# & 31.45\%@1\# & 29.61\%@1\# \\
\hline 6 & $50 \% @ 26$ & 46.68\%@26 & 49.91\%@26 \\
\hline \multirow{2}{*}{7} & 30\%@1\# & 28.01\%@1\# & 39.91\%@1\# \\
\hline & $50 \% @ 26$ & 54.44\%@26 & 64.93\%@26 \\
\hline
\end{tabular}

the girder, stringers, floor beams, and concrete piers, are modelled based on the 2-node beam element. And the bridge bearings are tackled with a spring element; for each direction, the spring constants are $k_{x}=3.17 \times 10^{6} \mathrm{~N} / \mathrm{m}$, $k_{y}=1.26 \times 10^{6} \mathrm{~N} / \mathrm{m}$, and $k_{z}=4.29 \times 10^{7} \mathrm{~N} / \mathrm{m}$, respectively. In addition, the detailed material properties can be referred to the paper [42]. After obtaining the finite element model, the natural frequencies and modal assurance criterion (MAC) are utilized to measure the correlation, which are listed in Table 3.

From the data listed in Table 3, it can be seen that the max error between analytical natural frequencies and measured ones is merely 3.22\%; meanwhile, the first six MAC values are all larger than 0.97 . The comparison indicates that the model shows a good reality to reflect the dynamic characteristics of the actual engineering structure, 


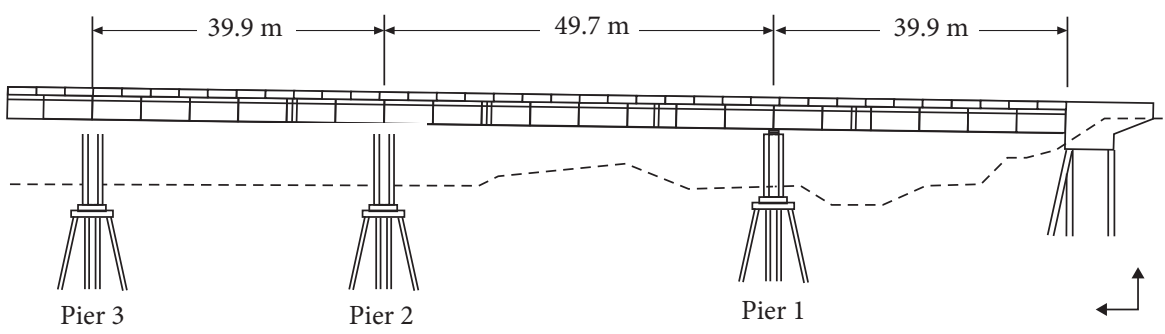

(a)

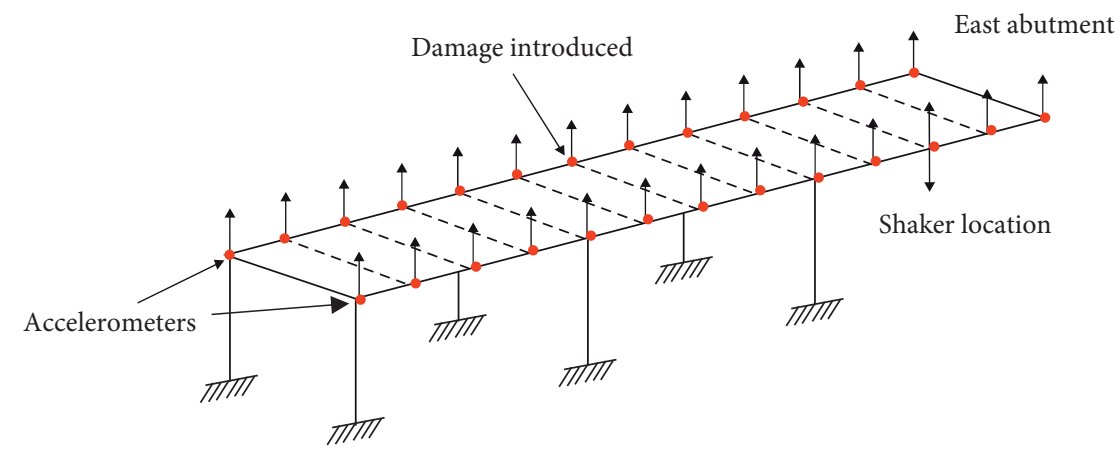

(b)

FIgURE 15: I-40 bridge: (a) overall layout; (b) experimental setup.

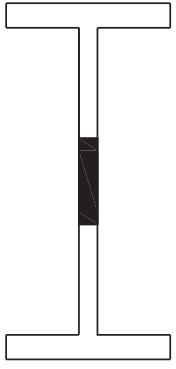

D-1

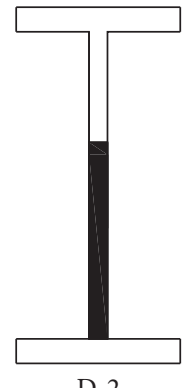

D-2

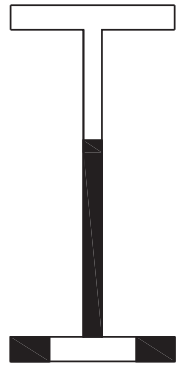

D-3

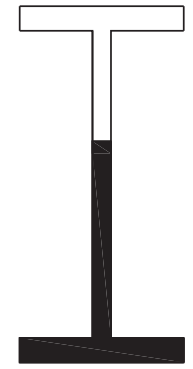

D-4
Figure 16: Damage cases of the I-40 bridge.

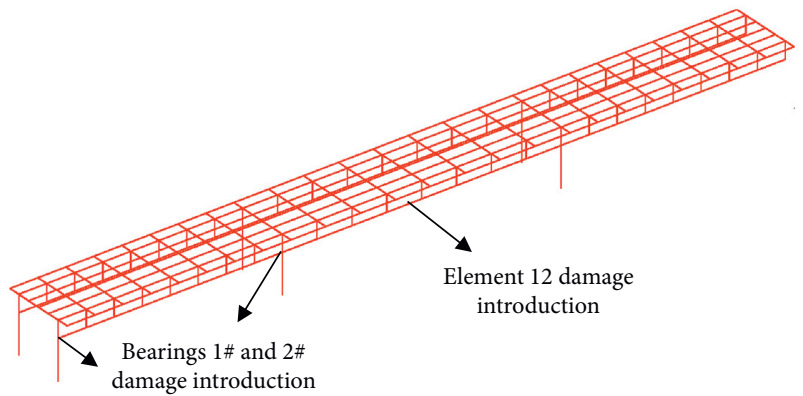

Figure 17: The finite element model of the I-40 bridge.

which can be adopted to implement the subsequent damage detection procedure.

4.2.2. Damage Identification and Results' Discussion. Based on the aforementioned actual damage cases and the finite element model, there are several simulated bearing damage cases that have been introduced to combine the
TABle 3: Analytical and measured natural frequencies and MAC.

\begin{tabular}{lcccc}
\hline Mode & Measured $(\mathrm{Hz})$ & Analytical $(\mathrm{Hz})$ & Error (\%) & MAC \\
\hline 1 & 2.4828 & 2.4821 & 0.03 & 0.9949 \\
2 & 2.9593 & 3.0016 & 1.41 & 0.9841 \\
3 & 3.4991 & 3.4176 & 2.38 & 0.9905 \\
4 & 4.0791 & 4.0365 & 1.06 & 0.9708 \\
5 & 4.1668 & 4.0369 & 3.22 & 0.9718 \\
6 & 4.6310 & 4.6561 & 0.54 & 0.9709 \\
\hline
\end{tabular}

actual structural element damage cases to verify the proposed bearing damage detection method. For each damage case, the first five natural frequencies and modal shapes are adopted to detect the damage of the structural element and bearing. The iterative number is defined as 20,000, and the initial value is 1 for every damage case. The damage cases and corresponding results can be seen in Table 4 .

As shown in Table 4, the proposed method can not only identify the single-type damage situation (e.g., only element damage or bearing damage) but also assess the multiple-type damage scenario accurately. In case D-1, the max identified error of the structural element is $0.21 \%$, and for the bearing, it is $1.89 \%$; for case $\mathrm{D}-2$, the max errors have emerged in D-2(d), which are $0.15 \%$ and $0.61 \%$ for the element and bearing, respectively. And for cases D-3 and D-4, the accuracies of damage detection have declined to some extent, namely, the max errors are $3.20 \%$ (D-3(c), element damage) and $4.84 \%$ (D-3(d), bearing damage), respectively.

In conclusion, although there are some negative influences of ambient temperature variations and environmental noise, the damage detection results are of great accuracy, which indicates the proposed method has good robustness. The uncertainties in the damage detection process can be overcome using the Bayesian framework; meanwhile, the 
TABle 4: Damage cases and identification results of the I-40 bridge.

\begin{tabular}{|c|c|c|c|c|c|}
\hline $\begin{array}{l}\text { Ambient temperature } \\
\left({ }^{\circ} \mathrm{C}\right)\end{array}$ & Case & $\begin{array}{c}\text { Damage severity @ element } \\
\text { number }\end{array}$ & $\begin{array}{c}\text { Damage severity @ bearing } \\
\text { number }\end{array}$ & $\begin{array}{l}\text { Detection } \\
\text { goal }\end{array}$ & $\begin{array}{l}\text { Identification } \\
\text { results }\end{array}$ \\
\hline \multirow{4}{*}{15.5} & $\begin{array}{l}\text { D- } \\
1(\mathrm{a})\end{array}$ & $5 \% @ 12$ & 1 & E & $5.12 \% @ 12$ \\
\hline & $\begin{array}{l}\mathrm{D}- \\
1(\mathrm{~b})\end{array}$ & $5 \% @ 12$ & $30 \% @ 1 \#$ & B & 29.94\%@1\# \\
\hline & $\mathrm{D}-1(\mathrm{c})$ & $5 \% @ 12$ & $30 \% @ 1 \#$ & $E$ and $B$ & $\begin{array}{l}5.25 \% @ 12 \\
31.89 \% @ 1 \#\end{array}$ \\
\hline & $\begin{array}{c}\text { D- } \\
1(\mathrm{~d})\end{array}$ & $5 \% @ 12$ & $\begin{array}{l}30 \% @ 1 \# \\
50 \% @ 2 \#\end{array}$ & $E$ and $B$ & $\begin{array}{l}5.21 \% @ 12 \\
30.10 \% @ 1 \# \\
49.48 \% @ 2 \#\end{array}$ \\
\hline \multirow{4}{*}{28.9} & $\begin{array}{c}\text { D- } \\
2(\mathrm{a})\end{array}$ & 10\%@12 & l & E & 10.1\%@12 \\
\hline & $\begin{array}{l}\mathrm{D}- \\
2(\mathrm{~b})\end{array}$ & 10\%@12 & $30 \% @ 1 \#$ & B & 29.99\%@1\# \\
\hline & $\mathrm{D}-2(\mathrm{c})$ & 10\%@ 12 & 30\%@1\# & $E$ and $B$ & $\begin{array}{l}10.09 \% @ 12 \\
29.99 \% @ 1 \#\end{array}$ \\
\hline & $\begin{array}{c}\text { D- } \\
2(d)\end{array}$ & 10\%@ @ 12 & $\begin{array}{l}30 \% @ 1 \# \\
50 \% @ 2 \#\end{array}$ & $E$ and $B$ & $\begin{array}{l}9.85 \% @ 12 \\
30.61 \% @ 1 \# \\
49.52 \% @ 2 \#\end{array}$ \\
\hline \multirow{4}{*}{26.1} & $\begin{array}{l}\text { D- } \\
3(\mathrm{a})\end{array}$ & $32 \% @ 12$ & I & E & $32.28 \% @ 12$ \\
\hline & $\begin{array}{c}\mathrm{D}- \\
3(\mathrm{~b})\end{array}$ & 32\%@12 & 30\%@1\# & B & 30.05\%@1\# \\
\hline & $\mathrm{D}-3(\mathrm{c})$ & 32\%@12 & 30\%@1\# & $E$ and $B$ & $\begin{array}{l}31.04 \% @ 12 \\
26.80 \% @ 1 \#\end{array}$ \\
\hline & $\begin{array}{l}\mathrm{D}- \\
3(\mathrm{~d})\end{array}$ & $32 \% @ 12$ & $\begin{array}{l}30 \% @ 1 \# \\
50 \% @ 2 \#\end{array}$ & $E$ and $B$ & $\begin{array}{c}31.56 \% @ 12 \\
30.95 \% @ 1 \# \\
49.51 \% @ 2 \#\end{array}$ \\
\hline \multirow{4}{*}{20.0} & $\begin{array}{l}\text { D- } \\
4(\mathrm{a})\end{array}$ & 92\%@12 & I & E & 91.77\%@12 \\
\hline & $\begin{array}{c}\mathrm{D}- \\
4(\mathrm{~b})\end{array}$ & $92 \% @ 12$ & 30\%@1\# & B & 30.07\%@1\# \\
\hline & $\mathrm{D}-4(\mathrm{c})$ & $92 \% @ 12$ & 30\%@1\# & $E$ and $B$ & $\begin{array}{l}92.88 \% @ 12 \\
26.93 \% @ 1 \#\end{array}$ \\
\hline & $\begin{array}{l}\text { D- } \\
4(\mathrm{~d})\end{array}$ & 92\%@12 & $\begin{array}{l}30 \% @ 1 \# \\
50 \% @ 2 \#\end{array}$ & $E$ and $B$ & $\begin{array}{l}92.20 \% @ 12 \\
21.38 \% @ 1 \# \\
54.84 \% @ 2 \#\end{array}$ \\
\hline
\end{tabular}

Note: $\mathrm{E}$ and $\mathrm{B}$ denote the element damage and bearing damage, respectively.

damage of the structural element and bearing can be detected simultaneously, which is very useful in the practical application. The proposed damage detection framework shows good potential for the bearing damage detection.

\section{Conclusions}

In this paper, firstly, based on the structural dynamics and finite element method, the structural dynamic characteristic equation considering uncertain conditions, such as environmental temperature variations, structural element damage, and bearing damage, has been proposed. Then, based on the proposed equation, the influences of the uncertain conditions have been evaluated firstly using a simply supported beam. After that, a damage detection method has been promoted by introducing the Bayesian damage detection theory and matrix perturbation method; in Bayesian damage detection theory, regarding the uncertainties of damage detection, the posterior probability density function of damage parameters is obtained based on the natural frequencies and modal shapes; at the same time, the matrix perturbation method is used to obtain the $2^{\text {nd }}$-order perturbation formulae of modal parameters, which can save the computational cost. Furthermore, a numerical example of an 8-span concrete continuous beam structure and a practical example of I-40 steel-concrete composite bridge are exploited to validate the effectiveness of the proposed method. There are some conclusions and outlooks that can be drawn as follows:

(1) The uncertain conditions, especially for the synergistic effects of multiple factors, can cause serious fluctuations of structural modal parameters; meanwhile, the fluctuations cannot be evaluated as a linear relationship, which will lead to inaccurate damage detection. Thus, uncertainties should be considered in the process.

(2) The proposed damage detection method is of great robustness and good damage identification accuracy, which is validated in the numerical example and 
practical engineering. It can identify the damage of the structural elements and bearings simultaneously under the distraction of uncertainties.

(3) The high accurate detection of bearing damage when the structural element exists indicates the proposed method can be applied to practical engineering, which means there is some possibility to develop a useful damage detection approach of structural bearings based on this idea.

(4) However, some extreme damage cases, for instance, most of the bearings and even all bearings of a structure are damaged, have not been studied. In this article, the most serious situation is one element and two bearings have been damaged, which means some further research studies need to be performed in the future.

\section{Data Availability}

The data used to support the findings of this study are available from the corresponding author upon request.

\section{Conflicts of Interest}

The authors declare that they have no conflicts of interest.

\section{Acknowledgments}

This study was supported by the Project of Science Research and Technological Development of Yulin City, Guangxi, China (20202927), the Science and Technology Research Planning Project (2018), the Educational Commission of Hubei Province, China (no. B2018051), the Nanning Excellent Young Scientist Program (RC20190108), and the Scientific Research Project of Department of Education of Hubei Province (B2019052): Study on interface bonding between steel strand and concrete of prestressed concrete bridge.

\section{References}

[1] C.-Y. Kim, D.-S. Jung, N.-S. Kim, S.-D. Kwon, and M. Q. Feng, "Effect of vehicle weight on natural frequencies of bridges measured from traffic-induced vibration," Earthquake Engineering and Engineering Vibration, vol. 2, no. 1, pp. 109-115, 2003.

[2] Y. Itoh and H. S. Gu, "Prediction of aging characteristics in natural rubber bearings used in bridges," Journal of Bridge Engineering, vol. 14, no. 2, pp. 122-128, 2009.

[3] J. Li, S. S. Law, and Y. Ding, "Substructure damage identification based on response reconstruction in frequency domain and model updating," Engineering Structures, vol. 41, no. 1, pp. 270-284, 2012.

[4] C.-D. Pan, L. Yu, H.-L. Liu, Z.-P. Chen, and W.-F. Luo, "Moving force identification based on redundant concatenated dictionary and weighted 11-norm regularization," Mechanical Systems and Signal Processing, vol. 98, no. 1, pp. 32-49, 2018.

[5] Z. Chen and L. Yu, "A new structural damage detection strategy of hybrid PSO with Monte Carlo simulations and experimental verifications," Measurement, vol. 122, no. 1, pp. 658-669, 2018.

[6] J. F. Gu, M. Gul, and X. G. Wu, "Damage detection under varying temperature using artificial neural networks," Structural Control and Health Monitoring, vol. 24, no. 11, Article ID e1998, 2017.

[7] S. Weng, H. P. Zhu, Y. Xia et al., "Damage detection using the eigenparameter decomposition of substructural flexibility matrix," Mechanical Systems and Signal Processing, vol. 34, no. 1-2, pp. 19-38, 2013.

[8] S. Weng, H. P. Zhu, R. X. Gao et al., "Identification of free-free flexibility for model updating and damage detection of structures," Journal of Aerospace Engineering, vol. 31, no. 3, Article ID 04018017, 2018.

[9] S. Weng, H. Zhu, Y. Xia, J. Li, and W. Tian, "A review on dynamic substructuring methods for model updating and damage detection of large-scale structures," Advances in Structural Engineering, vol. 23, no. 3, pp. 584-600, 2020.

[10] C. S. N. Pathirage, J. Li, L. Li, H. Hao, W. Liu, and P. Ni, "Structural damage identification based on autoencoder neural networks and deep learning," Engineering Structures, vol. 172, no. 1, pp. 13-28, 2018.

[11] Z. Chen, H. Fang, X. Ke, and Y. Zeng, "A new method to identify bridge bearing damage based on Radial Basis Function Neural Network," Earthquakes and Structures, vol. 11, no. 5, pp. 841-859, 2016.

[12] Y. Ni, C. Liu, E. Gao et al., "Research on damage index of bridge pot rubber bearing based on correlation and sensitivity analysis and SVM," in Proceedings Of 2020 International Conference On Urban Engineering And Management Science, pp. 305-309, IEEE, Zhuhai, China, March 2020.

[13] M. Huang and Y. Lei, "Bearing damage detection of a reinforced concrete plate based on sensitivity analysis and chaotic moth-flame-invasive weed optimization," Sensors, vol. 20, no. 19, p. 5488, 2020.

[14] Y. Xia, B. Chen, S. Weng, Y.-Q. Ni, and Y.-L. Xu, "Temperature effect on vibration properties of civil structures: a literature review and case studies," Journal of Civil Structural Health Monitoring, vol. 2, no. 1, pp. 29-46, 2012.

[15] Z. Ding, J. Li, and H. Hai, "Structural damage identification using improved Jaya algorithm based on sparse regularization and Bayesian inference," Mechanical Systems and Signal, vol. 132, no. 1, pp. 211-231, 2020.

[16] R. Hou, X. Wang, Q. Xia, and Y. Xia, "Sparse Bayesian learning for structural damage detection under varying temperature conditions," Mechanical Systems and Signal Processing, vol. 145, no. 1, Article ID 106965, 2020.

[17] X. Y. Wang, R. R. Hou, Y. Xia et al., "Structural damage detection based on variational Bayesian inference and delayed rejection adaptive Metropolis algorithm," Structural Health Monitoring, vol. 1, Article ID 1475921720921256, 2020.

[18] H. H. Khodaparast, J. E. Mottershead, and K. J. Badcock, "Interval model updating with irreducible uncertainty using the Kriging predictor," Mechanical Systems and Signal Processing, vol. 25, no. 4, pp. 1204-1226, 2011.

[19] R. Rocchetta, M. Broggi, Q. Huchet, and E. Patelli, "On-line bayesian model updating for structural health monitoring," Mechanical Systems and Signal Processing, vol. 103, no. 1, pp. 174-195, 2018.

[20] T. Huang and K.-U. Schröder, “A Bayesian probabilistic approach for damage identification in plate structures using responses at vibration nodes," Mechanical Systems and Signal Processing, vol. 146, no. 1, Article ID 106998, 2021. 
[21] M. Fallahian, F. Khoshnoudian, and V. Meruane, "Ensemble classification method for structural damage assessment under varying temperature," Structural Health Monitoring, vol. 17, no. 4 , pp. 747-762, 2018.

[22] V. Meruane and W. Heylen, "Structural damage assessment under varying temperature conditions," Structural Health Monitoring: An International Journal, vol. 11, no. 3, pp. 345-357, 2012.

[23] M. Rezaiee-Pajand, H. Sarmadi, and A. Entezami, "A hybrid sensitivity function and Lanczos bidiagonalization-Tikhonov method for structural model updating: application to a fullscale bridge structure," Applied Mathematical Modelling, vol. 89, no. 1, pp. 860-884, 2021.

[24] Z. Shi, Y. Hong, and S. Yang, "Updating boundary conditions for bridge structures using modal parameters," Engineering Structures, vol. 196, no. 1, Article ID 109346, 2019.

[25] H. Nick, A. Aziminejad, and M. Laknejadi, "Damage identification in steel girder bridges using modal strain energybased damage index method and artificial neural network," Engineering Failure Analysis, vol. 119, no. 1, Article ID 105010, 2021.

[26] Z. Ding, J. Li, and H. Hao, "Structural damage identification using improved Jaya algorithm based on sparse regularization and Bayesian inference," Mechanical Systems and Signal Processing, vol. 132, no. 1, pp. 211-231, 2019.

[27] Z. Ding, J. Li, H. Hao, and Z.-R. Lu, "Structural damage identification with uncertain modelling error and measurement noise by clustering based tree seeds algorithm," Engineering Structures, vol. 185, no. 1, pp. 301-314, 2019.

[28] D.-C. Du, H.-H. Vinh, V.-D. Trung, N.-T. Hong Quyen, and N.-T. Trung, "Efficiency of Jaya algorithm for solving the optimization-based structural damage identification problem based on a hybrid objective function," Engineering Optimization, vol. 50, no. 8, pp. 1233-1251, 2018.

[29] S. M. Seyedpoor, "A two stage method for structural damage detection using a modal strain energy based index and particle swarm optimization," International Journal of Non-linear Mechanics, vol. 47, no. 1, pp. 1-8, 2012.

[30] H. Y. Gao, X. L. Guo, and M. Y. Wu, "Study on identification of structural boundary using frequency parameterization," Applied Mechanics and Materials, vol. 78, no. 1, pp. 47284735, 2011.

[31] M. S. Huang, M. Gul, and H. P. Zhu, "Vibration-based structural damage identification under varying temperature effects," Journal of Aerospace Engineering, vol. 31, no. 3, Article ID 04018014.

[32] M. S. Huang, Y. Z. Lei, X. F. Li et al., "Damage identification of bridge structures considering temperature variations-based SVM and MFO," Journal of Aerospace Engineering, vol. 34, no. 2, Article ID 04020113, 2020.

[33] M. Huang, X. Li, Y. Lei, and J. Gu, "Structural damage identification based on modal frequency strain energy assurance criterion and flexibility using enhanced Moth-Flame optimization," Structures, vol. 28, no. 1, pp. 1119-1136, 2020.

[34] J. L. Beck and K.-V. Yuen, "Model selection using response measurements: bayesian probabilistic approach," Journal of Engineering Mechanics, vol. 130, no. 2, pp. 192-203, 2004

[35] Z. P. Chen and L. Yu, "A novel PSO-based algorithm for structural damage detection using Bayesian multi-sample objective function," Structural Engineering and Mechanics, vol. 63, no. 6, pp. 825-835, 2017.

[36] T. Yin, H.-p. Zhu, and S.-j. Fu, "Damage identification of periodically-supported structures following the Bayesian probabilistic approach," International Journal of Structural
Stability and Dynamics, vol. 19, no. 01, Article ID 1940011, 2019.

[37] M. Georgioudakis and V. Plevris, "A combined modal correlation criterion for structural damage identification with noisy modal data," Advances in Civil Engineering, vol. 2018, Article ID 3183067, 20 pages, 2018.

[38] D. Dinh-Cong, T. Vo-Duy, and T. Nguyen-Thoi, "Damage assessment in truss structures with limited sensors using a two-stage method and model reduction," Applied Soft Computing, vol. 66, no. 1, pp. 264-277, 2018.

[39] L. Mao, S. Weng, S.-J. Li, H.-P. Zhu, and Y.-H. Sun, "Statistical damage identification method based on dynamic response sensitivity," Journal of Low Frequency Noise, Vibration and Active Control, vol. 39, no. 3, pp. 560-571, 2020.

[40] D. Dinh-Cong, T. Vo-Duy, V. Ho-Huu, H. Dang-Trung, and T. Nguyen-Thoi, "An efficient multi-stage optimization approach for damage detection in plate structures," Advances in Engineering Software, vol. 112, no. 1, pp. 76-87, 2017.

[41] C. R. Farrar, S. W. Doebling, P. J. Cornwell et al., Variability of Modal Parameters Measured on the Alamosa Canyon Bridge, USA, 1996.

[42] M. Huang, Y. Lei, and S. Cheng, "Damage identification of bridge structure considering temperature variations based on particle swarm optimization - cuckoo search algorithm," Advances in Structural Engineering, vol. 22, no. 15, pp. 3262-3276, 2019. 